\title{
Stepping stones to the future of haemoglobin-based blood products: clinical, preclinical and innovative examples
}

Satué, Clara Coll; Bishnoi, Shahana; Chen, Jiantao; Hosta-Rigau, Leticia

Published in:

Biomaterials Science

Link to article, DOI:

10.1039/d0bm01767a

Publication date:

2021

Document Version

Peer reviewed version

Link back to DTU Orbit

Citation (APA):

Satué, C. C., Bishnoi, S., Chen, J., \& Hosta-Rigau, L. (2021). Stepping stones to the future of haemoglobinbased blood products: clinical, preclinical and innovative examples. Biomaterials Science, 9, 1135-1152. https://doi.org/10.1039/d0bm01767a

\section{General rights}

Copyright and moral rights for the publications made accessible in the public portal are retained by the authors and/or other copyright owners and it is a condition of accessing publications that users recognise and abide by the legal requirements associated with these rights.

- Users may download and print one copy of any publication from the public portal for the purpose of private study or research.

- You may not further distribute the material or use it for any profit-making activity or commercial gain

- You may freely distribute the URL identifying the publication in the public portal 


\title{
Stepping stones to the future of haemoglobin-based blood products: clinical, preclinical and innovative examples
}

\author{
Clara Coll-Satue, ${ }^{\dagger}$ Shahana Bishnoi, ${ }^{+}$Jiantao Chen $^{+}$and Leticia Hosta-Rigau*
}

DOI: $10.1039 / x 0 x x 00000 x$

There is an enormous demand for blood transfusions in daily clinical practices since blood products, and especially red blood cells (RBCs), can significantly improve survival. However, donor-derived RBCs have also important limitations as a result of their insufficient availability, the need for typing and crossmatching, short self-life or risk of pathogenic contamination. Thus, as a result of the unique oxygen-transport ability of hemoglobin $(\mathrm{Hb}), \mathrm{Hb}$-based oxygen carriers (HBOCs) have attracted a lot of attention for the development of RBCs surrogates able to provide tissue oxygenation. Here, we highlight the progress in the development of HBOCs, placing the focus on the different examples that have undergone exhaustive pre-clinical and clinical evaluation. Additionally, we also provide a comprehensive review of very recent and innovative examples depicting the pipeline of the next generation of blood substitutes.

\section{Introduction}

The transfusion of whole blood but also of various isolated components (e.g., packed red blood cells (RBCs), platelet concentrates or plasma) is an indispensable and common clinical procedure. Specifically, blood transfusions are widely employed in conditions of serious blood disorders such as anaemia, haemophilia or for patients receiving tumour chemotherapy. ${ }^{1}$ Additionally, blood transfusions are also extensively used in the context of traumatic injuries and surgical operations (e.g., transplants). ${ }^{2}$

Despite its many advantages, the use of donor blood has several limitations and risks. For example, there is a limited availability since only $10 \%$ of eligible donors are actually donating blood. ${ }^{3}$ Unfortunately, this blood short supply is expected to get worse due to increased population growth and aging. What is more, only $7 \%$ of the donors have blood that can be immediately used in emergencies (i.e., "universal" O-negative blood). ${ }^{3}$ Thus, before blood can be transfused, there is a need for cross-matching and blood group typing which can cause fatal delays in emergency situations. Blood-based products have a short storage lifetime of a maximum of 42 days in refrigerated conditions and 1 day at room temperature. This short self-life makes it impossible to create large stockpiles to be used in acute disasters (e.g., earthquakes, plan crashes or terrorist attacks). The need for refrigerated conditions creates major logistical challenges when donor blood is needed in austere and remote battlefield or civilian locations. ${ }^{4-}$ ${ }^{6}$ Also, both RBCs and platelets develop storage lesions over time affecting their stability, physiology as well as their in vivo circulation time. ${ }^{7,8}$ For example, while RBCs can circulate in the bloodstream for about 120 days, this time is reduced to only 28 days for donor RBCs. Blood products are also a transmission vector for infectious diseases such as human immunodeficiency (HIV) virus, Zika virus and hepatitis B or C. This results in extensive and costly screening prior to transfusion. ${ }^{3,9}$ Lastly, of the 75 million units of RBCs that are collected worldwide, 13 million are currently not being tested for HIV. ${ }^{10}$

While research efforts are focusing on resolving these issues to enhance the availability and applicability of donor-derived blood products, ${ }^{11-14}$ in parallel, a robust volume of research is being devoted to create semi- or fully-synthetic artificial oxygen $\left(\mathrm{O}_{2}\right)$ carriers. It is envisioned that such an approach will revolutionize the practices in blood banking and transfusion medicine. ${ }^{15}$ Artificial $\mathrm{O}_{2}$ carriers are being specifically designed to substitute and even amplify the functions of endogenous blood components. Additionally, such a (semi)-synthetic platform will have several advantages over donor blood including: sufficient availability, since it can be produced at a large scale; prolonged storage across a wide range of environmental conditions, thus having easy storage and portability; absence of disease transmission, since they could be sterilized without compromising their functionality; universal application since they are absent of blood group antigens thus avoiding the need for typing and cross-matching. ${ }^{16,17}$ 
In this review, we first provide an overview of the biology of RBCs and haemoglobin ( $\mathrm{Hb}$ ). Next, we feature the most successful and recent examples of different $\mathrm{Hb}$-based oxygen carriers (HBOCs). The different examples will be classified depending on their development status (i.e., marketed products, clinical or preclinical developments). The most novel and innovative designs will also be discussed at the end of the section.

\section{RBCs and $\mathrm{Hb}$}

RBCs, also known as erythrocytes, haemocytes or red corpuscles, are the most prevalent cell type since they constitute approximately $84 \%$ of all the cells of our body. ${ }^{18}$ In an adult healthy person, every second, the bone marrow produces and releases into the circulation between 2 and 3 million RBCs. ${ }^{19}$

RBCs are flexible oval disks of about $7.5-8.7 \mu \mathrm{m}$ in diameter and around $2 \mu \mathrm{m}$ in thickness (Scheme 1A). They display a biconcave shape in order to increase their surface area for optimal $\mathrm{O}_{2}$ diffusion. RBCs are also highly flexible with a Young's modulus of only 10-20 kPa. This deformability allows them to change their shape and morphology when passing through the smallest blood vessels (i.e., capillaries of 5-10 $\mu \mathrm{m}$ in diameter). ${ }^{20,21}$ Thanks to a two-dimensional spectrin network located in the cytosolic side of their membrane, RBCs are highly viscoelastic. This allows them to preserve their mechanical integrity following cyclical deformation in the microvasculature. Importantly, when oxygenated, RBCs are significantly more deformable than when they are in a deoxygenated state, thus making it possible to squeeze through and deliver $\mathrm{O}_{2}$ to the microvasculature.

Furthermore, the size, shape and flexibility of RBCs determine their hemodynamic distribution in the blood flow. In mid to large blood vessels, RBCs are located in the center of the parabolic flow field. In the small capillaries, RBCs are distributed throughout the vessels for efficient $\mathrm{O}_{2}$ exchange. ${ }^{22}$ Each $\mathrm{RBC}$ remains in circulation for about 120 days and, the clearance of old or damaged $\mathrm{RBC}$, is carried out by macrophages residing in the liver and the spleen. ${ }^{23}$

Since $\mathrm{O}_{2}$ is approximately 20 times less soluble in the aqueous phase than carbon dioxide $\left(\mathrm{CO}_{2}\right)$, an $\mathrm{O}_{2}$ transport system is required to achieve the high $\mathrm{O}_{2}$ demands of our body. ${ }^{3}$ This function is conducted by $\mathrm{Hb}$, which is the main component of $\mathrm{RBCs}$. $\mathrm{Hb}$ is responsible for the transport of $98 \%$ of all the $\mathrm{O}_{2}$ while the remaining $2 \%$ is dissolved in blood plasma. In an adult human, around 250 million $\mathrm{Hb}$ molecules with a weight of 27-31 pg can be found in each RBC. This accounts for one third of the total volume of a RBC. In fact, to allow for a high Hb loading, mature human RBCs do not have a nucleus and are missing most of the organelles present in other eukaryotic cells (e.g., mitochondria or Golgi apparatus). $\mathrm{Hb}$ is a tetrameric protein with a molecular weight of 64.5 kDa. As suggested by its name, $\mathrm{Hb}$ is constituted by "heme groups" (non-protein part) and "globins" (protein part). Specifically, Hb is composed of two alpha and two beta subunits $(\alpha 1 \beta 1 \alpha 2 \beta 2)$ and each subunit contains a heme group and a polypeptide globulin chain (Scheme 1B). The alpha globulin chains consist of 141 amino acid residues and the beta chains are slightly bigger with 146
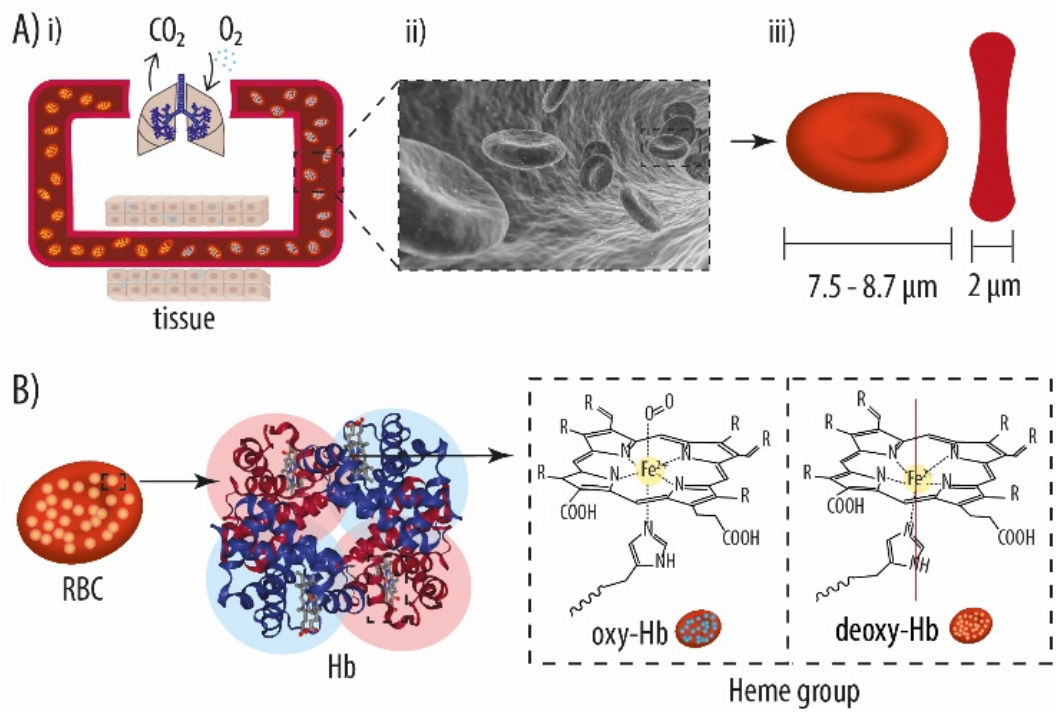

Scheme 1. A) i) Schematic illustration of red blood cells (RBCs) travelling from the lungs (oxygen $\left(\mathrm{O}_{2}\right.$ )-loading site) to the tissues where $\mathrm{O}_{2}$ is released. The RBCs also carry carbon dioxide $\left(\mathrm{CO}_{2}\right)$ from the tissues and to the lungs for excretion. Schematic representation of RBCs circulating within a blood vessel (ii) and showing their diameter and thickness (iii). B) Multi-scale representation of RBCs and haemoglobin ( $\mathrm{Hb}$ ). $\mathrm{Hb}$ is composed by two alpha (red) and two beta (blue) subunits constituting the "globins" (protein part). Each globin contains a heme group in the centre (non-protein part) which changes conformation from an oxygenated (oxy-Hb) to a deoxygenated (deoxy-Hb) state. 
amino acids. ${ }^{24}$ The heme group is comprised by a protoporphyrin ring with an iron ion bound to the centre, which is responsible for $\mathrm{O}_{2}$ transport. Since each iron ion can carry one $\mathrm{O}_{2}$ molecule, a total of four $\mathrm{O}_{2}$ can be transported by each $\mathrm{Hb}$. Importantly, for $\mathrm{O}_{2}$ transport, the iron ion must be in the reduced state (ferrous form: $\mathrm{Fe}^{2+}$ ).

Throughout the bloodstream, $\mathrm{Hb}$ is exposed to different partial $\mathrm{O}_{2}$ pressures $\left(\mathrm{pO}_{2}\right)$ and the $\mathrm{O}_{2}$ binding kinetics to $\mathrm{Hb}$ are positively cooperative. This means that, a small variation in $\mathrm{pO}_{2}$, results in a large change in the amount of $\mathrm{O}_{2}$ captured or released by $\mathrm{Hb}$. Thus, in the lungs, where there is a high $\mathrm{pO}_{2}, \mathrm{Hb}$ predominates in the relaxed state ( $\mathrm{R}$-state) displaying a high affinity for $\mathrm{O}_{2}(\mathrm{Scheme}$ 2A). In this R-state, $\mathrm{Hb}$ readily binds to $\mathrm{O}_{2}$ (oxy- $\mathrm{Hb}$ ). As a result, within the lung capillaries, $\mathrm{Hb}$ is nearly saturated with around $98 \%$ of its $\mathrm{O}_{2}$-binding sites occupied. However, as blood transits from the lungs to the tissues with a lower $\mathrm{pO}_{2}, \mathrm{Hb}_{\mathrm{changes}}$ its conformation to the tense state (T-state). In the T-state, also known as the unbound state (deoxy-Hb), $\mathrm{Hb}$ has a low affinity towards $\mathrm{O}_{2}$, thus promoting its release into the tissues. ${ }^{25}$

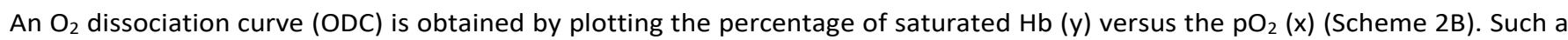
curve displays a sigmoidal shape highlighting that $\mathrm{O}_{2}$ binding takes place in a positively cooperative fashion. The ODC shows a plateau for high $\mathrm{pO}_{2}$ indicating complete saturation of $\mathrm{Hb}$. Several physiological factors can influence the $\mathrm{O}_{2}$ binding kinetics to $\mathrm{Hb}$ and this will result on shift for the ODC. Specifically, an increase in the $\mathrm{CO}_{2}$ partial pressure $\left(\mathrm{pCO}_{2}\right)$, the concentration of the allosteric effector 2,3-diphosphoglycerate (2,3-DPG), the temperature or a decrease in pH (acidity), promote the T-state and the release of $\mathrm{O}_{2}$ into the tissues. In contrast, lower $\mathrm{pCO}_{2}, 2,3-\mathrm{DPG}$ concentration, temperature or higher pH (alkalinity), will result on a leftward shift, promoting the R-state and consequently enhancing the $\mathrm{O}_{2}$ binding. ${ }^{26}$ The $\mathrm{p} 50$, which is defined as the $\mathrm{pO}_{2}$ at which $\mathrm{Hb}$ is $50 \%$ saturated with $\mathrm{O}_{2}$, is a good indication of $\mathrm{Hb}^{\prime}$ s affinity for $\mathrm{O}_{2}$. Thus, for high p50 values, $\mathrm{Hb}^{\prime}$ s affinity for $\mathrm{O}_{2}$ decreases while low p50 values result on a left shift of the ODC and the corresponding high $\mathrm{O}_{2}$ affinity. The p50 of $\mathrm{Hb}$ encapsulated within RBCs corresponds to $26.6 \mathrm{mmHg} .27,28$

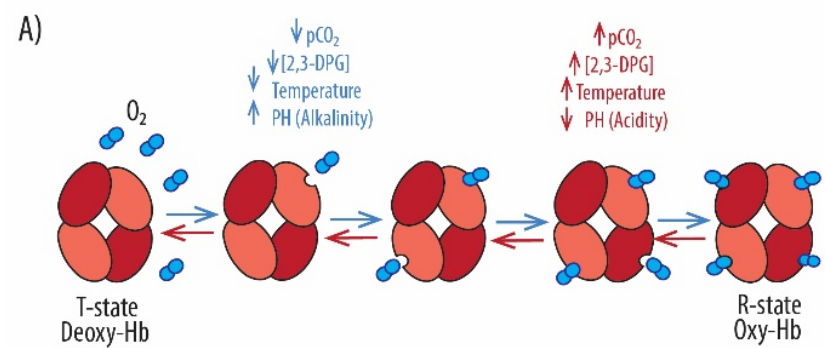

B)

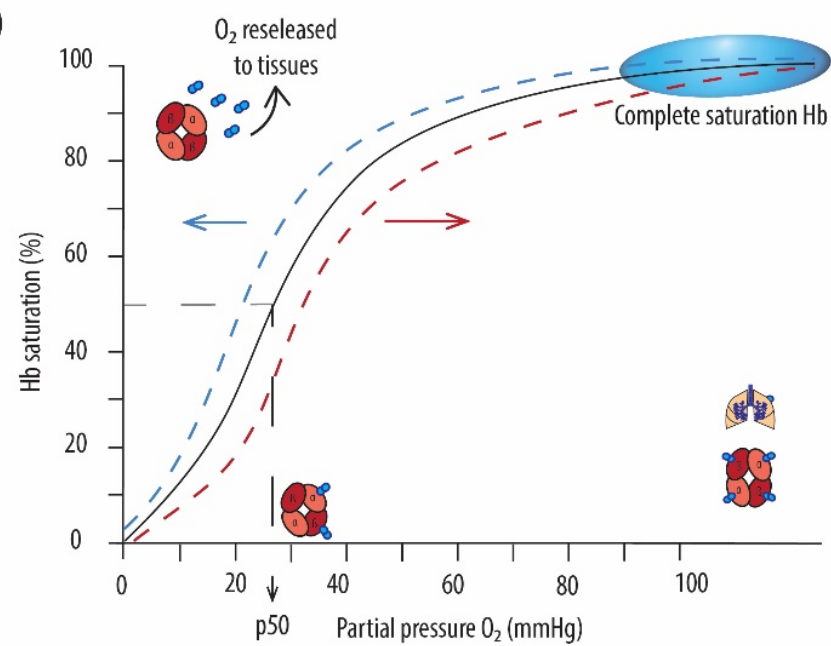

Scheme 2. A) Schematic representation of the different conformations of haemoglobin $(\mathrm{Hb})$ depending on the partial oxygen $\left(\mathrm{O}_{2}\right)$ pressure $\left(\mathrm{pO}_{2}\right)$. In the tense state (T-state) or unbound state (deoxy- $\mathrm{Hb}$ ), $\mathrm{Hb}$ has a low affinity towards $\mathrm{O}_{2}$ promoting its release into the tissues. However, when the first molecule of $\mathrm{O}_{2}$ binds to $\mathrm{Hb}$, a conformational change in the $\mathrm{Hb}^{\prime} \mathrm{s}$ structure increases the $\mathrm{O}_{2}$ affinity favouring the binding of more $\mathrm{O}_{2}$ molecules and facilitating the transition to the relaxed state (R-state) where $\mathrm{Hb}$ binds to $\mathrm{O}_{2}$ (oxy$\mathrm{Hb}$ ). Several physiological factors such as temperature $(\mathrm{T}), \mathrm{pH}$, concentration of 2,3 diphosphoglycerate (2,3-DPG) or partial carbon dioxide pressure $\left(\mathrm{pCO}_{2}\right)$ facilitate either the $\mathrm{T}$ - or the R-state. B) Representation of $\mathrm{Hb} \mathrm{O}_{2}$ dissociation curve with the characteristic sigmoidal shape highlighting $\mathrm{Hb}^{\prime}$ 's positive cooperativity. The plateau reached at high $\mathrm{pO}_{2}$ indicates complete saturation of $\mathrm{Hb}$. The $\mathrm{p} 50$ indicates the $\mathrm{pO}_{2}$ at which $\mathrm{Hb}$ is $50 \%$ saturated with $\mathrm{O}_{2}$. 
The amount of $\mathrm{CO}_{2}, \mathrm{pH}$ (as concentration of proton ions $\left(\mathrm{H}^{+}\right)$) and the resulting $\mathrm{O}_{2}$ affinity, are highly interrelated parameters (Scheme 3). $\mathrm{CO}_{2}$ can be transported in the bloodstream in three different ways. A small part of $\mathrm{CO}_{2}$ can be dissolved in blood plasma ( 10\%) (Scheme 3A) while, the majority of the $\mathrm{CO}_{2}(\sim 85 \%)$, is transported as bicarbonate $\left(\mathrm{HCO}_{3}{ }^{-}\right)$, which is water soluble. The enzyme carbonic anhydrase (CA) within RBCs is responsible for catalysing the hydration of $\mathrm{CO}_{2}$ into $\mathrm{HCO}_{3}^{-}$while releasing a $\mathrm{H}^{+}$ (Scheme 3B). ${ }^{29} \mathrm{~A}$ small $\mathrm{CO}_{2}$ amount ( $\left.5 \%\right)$ can be transported bound to $\mathrm{Hb}$ by forming carbaminohaemoglobin $\left(\mathrm{CO}_{2}-\mathrm{Hb}\right)(\mathrm{Scheme}$ $3 \mathrm{C}$ ). Upon binding of $\mathrm{CO}_{2}$ to $\mathrm{Hb}$, an additional $\mathrm{H}^{+}$is generated. The association of the two $\mathrm{H}^{+}$with the imidazole groups of the histidine amino acids within $\mathrm{Hb}$, is responsible for $\mathrm{Hb}$ 's conformational change and the $\mathrm{O}_{2}$ unloading into the tissues (Scheme 3D). ${ }^{30}$ Such a phenomenon is known as the "Bohr effect". Importantly, this binding of excess $\mathrm{H}^{+}$onto $\mathrm{Hb}^{\prime}$ ' histidine moieties, also mitigates the corresponding acidosis and its detrimental effects. While the as-produced $\mathrm{HCO}_{3}{ }^{-}$diffuses out of the RBCs following a concentration gradient; chloride anions diffuse in, in order to maintain the electrical neutrality (Scheme $3 \mathrm{E}$ ). ${ }^{31}$ This phenomenon where $\mathrm{O}_{2}$ affects $\mathrm{Hb}^{\prime}$ 's affinity for both $\mathrm{CO}_{2}$ and $\mathrm{H}^{+}$is known as the "Haldane effect" and plays a central role in regulating the $\mathrm{O}_{2}$ and $\mathrm{CO}_{2}$ transport as well as the $\mathrm{pH}$ in the bloodstream.

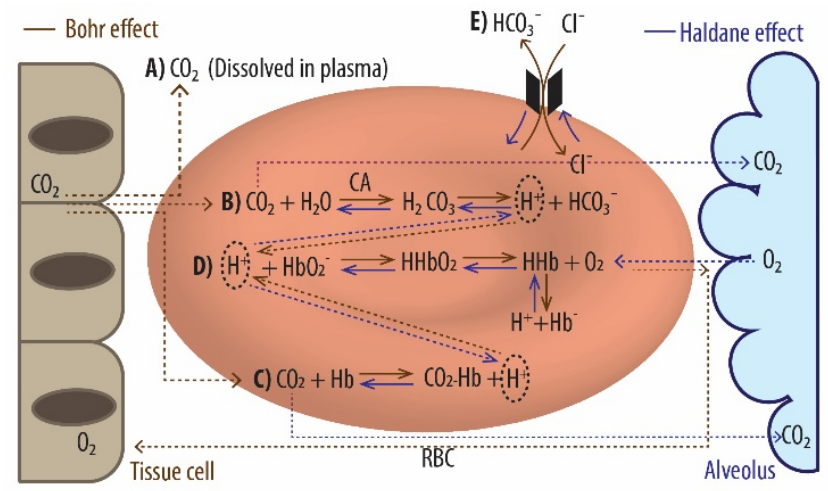

Scheme 3. Schematic illustration of the oxygen $\left(\mathrm{O}_{2}\right)$ and carbon dioxide $\left(\mathrm{CO}_{2}\right)$ between tissues, red blood cells (RBCs) and alveoli showing the Bohr (brown lines) and Haldane (blue lines) effect. $\mathrm{CO}_{2}$ is transported in the bloodstream dissolved in plasma (A), as bicarbonate $\left(\mathrm{HCO}_{3}{ }^{-}\right)$(B) or bound to haemoglobin ( $\left.\mathrm{Hb}\right)$ forming carbaminohaemoglobin $\left(\mathrm{CO}_{2}-\mathrm{Hb}\right)(\mathrm{C})$. The Bohr effect explains $\mathrm{Hb}^{\prime}$ 's ability to decrease $\mathrm{O}_{2}$ affinity while increasing the affinity for both $\mathrm{CO}_{2}$ and proton ions $\left(\mathrm{H}^{+}\right)$. In the peripheral circulation, where there is a high $\mathrm{CO}_{2}$ partial pressure, the diffusion of $\mathrm{CO}_{2}$ into the RBCs is facilitated. Inside the RBCs, $\mathrm{CO}_{2}$ reacts with water $\left(\mathrm{H}_{2} \mathrm{O}\right)$ to generate $\mathrm{HCO}_{3}{ }^{-}$and $\mathrm{H}^{+}$in a reaction catalysed by the enzyme carbonic anhydrase (CA) (B). The resulting $\mathrm{H}^{+}$readily bind to oxy- $\mathrm{Hb}\left(\mathrm{HbO}_{2}^{-}\right)$promoting a change in its conformation from the R- to the T-state and releasing $\mathrm{O}_{2}$ to the tissues (D). $\mathrm{HCO}_{3}{ }^{-}$is transported outside the RBCs following a concentration gradient and chloride anions $\left(\mathrm{Cl}^{-}\right)$enter in the RBC in order to maintain the electrical neutrality $(\mathrm{E})$. The Haldane effect explains the ability of $\mathrm{Hb}$ to bind $\mathrm{O}_{2}$ displacing $\mathrm{CO}_{2}$ and $\mathrm{H}^{+}$. Specifically, in the pulmonary circulation, the high $\mathrm{O}_{2}$ partial pressure facilitates the $\mathrm{O}_{2}$ diffusion into the RBCs where readily binds to $\mathrm{Hb}(\mathrm{D})$. This binding results on a conformational change in $\mathrm{Hb}^{\prime}$ 's from the $\mathrm{T}$ - to the R-state facilitating $\mathrm{H}^{+}$release. The generated $\mathrm{H}^{+}$reacts with $\mathrm{HCO}_{3}{ }^{-}$to form $\mathrm{CO}_{2}$ and $\mathrm{H}_{2} \mathrm{O}(\mathrm{B})$ in a reaction catalysed by $\mathrm{CA} . \mathrm{CO}_{2}$ diffuses out of the $\mathrm{RBC}$ to be exhaled in the lungs. $\mathrm{HCO}_{3}{ }^{-} / \mathrm{Cl}^{-}$anion exchanger enables the entrance of $\mathrm{HCO}_{3}{ }^{-}$to the $\mathrm{RBC}$ in order to compensate the decrease in $\mathrm{HCO}_{3}{ }^{-}$concentration (E). $\mathrm{Cl}$ is transported out of the RBC to maintain electrical neutrality.

Within RBCs, $\mathrm{Hb}$ is exposed to different endogenous and exogenous agents oxidizing it to methemoglobin (metHb). Within metHb, the heme iron is in its oxidized ferric state $\left(\mathrm{Fe}^{3+}\right)$ and is not able to bind $\mathrm{O}_{2}$. Every 24 hours, $3 \%$ of all $\mathrm{Hb}$ is oxidized into metHb producing reactive oxygen species (ROS) as by-products. However, this process is accelerated under oxidative stress conditions or in the settings of increased $\mathrm{O}_{2}$ delivery. In particular, hydrogen peroxide $\left(\mathrm{H}_{2} \mathrm{O}_{2}\right)$ can react with both $\mathrm{Fe}^{2+}$ and $\mathrm{Fe}^{3+} \mathrm{Hb}^{2}$, resulting in heme degradation and the subsequent release of the free iron ions. These free iron ions can take part, together with $\mathrm{H}_{2} \mathrm{O}_{2}$, in the Haber-Weiss or Fenton reaction generating hydroxyl radicals $(\mathrm{OH} \cdot) \cdot{ }^{30}$ These resulting ROS have a very short life since they rapidly participate in a wide variety of reactions increasing toxicity. As an example, ROS can react with nitric oxide (NO) producing metHb and nitrate $\left(\mathrm{NO}_{3}{ }^{-}\right) \cdot{ }^{32} \mathrm{NO}$ being an important signalling molecule and a natural vasodilator, its depletion from the bloodstream results in vasoconstriction and the subsequent cardiovascular complications. ${ }^{33}$ Fortunately, natural RBCs are well equipped with mechanisms to prevent oxidation. In particular, cytochrome-b5 reductase using NADH as a co-factor, maintains metHb levels below $1 \% .{ }^{34}$ The enzyme metHb reductase, which also uses the NADH co-factor, has the ability to revert Hb's auto-oxidation. Antioxidant enzymes such as superoxide dismutase (SOD), catalase (CAT) and glutathione peroxidase (GPx) prevent ROS generation and thus contribute to RBCs function and integrity. RBCs also present high concentrations of antioxidant vitamins (ascorbic acid, $\alpha$ - 
tocopherol) and other antioxidant compounds such as reduced glutathione (GSH) or ferritin, which can scavenge free iron ions preventing the formation of $\mathrm{OH}^{-}$. Importantly, failure to reverse metHb formation not only diminishes the $\mathrm{O}_{2}$-carrying capacity of RBCs but also impairs Hb's positive cooperativity resulting in an increased affinity for $\mathrm{O}_{2}$ for the remaining ferrous heme groups. This also leads to dysregulated vascular tone and inflammatory reactions. ${ }^{2}$

\section{3. $\mathrm{Hb}$-based $\mathrm{O}_{2}$ carriers (HBOCs)}

$\mathrm{HBOCs}$ are semi-synthetic systems that make use of the excellent $\mathrm{O}_{2}$ carrying and delivering properties of natural $\mathrm{Hbs}$. The idea is to eliminate the toxic effects of free $\mathrm{Hb}$ to create a RBC surrogate to be used when donor RBCs are not available. The toxicity of acellular $\mathrm{Hb}$ mainly results from the tetramer dissociation into dimers and monomers, which can then permeate in between the endothelial cells lining our blood vessels into the smooth muscle tissue. ${ }^{35,36}$ There, they rapidly scavenge NO promoting the subsequent cardiovascular problems resulting from vasoconstriction. ${ }^{37}$ Additionally, free $\mathrm{Hb}$ affects the osmolarity of blood thus leading to alteration of blood volumes and associated side effects. Therefore, as a result of all these shortcomings, a substantial amount of research has been devoted to stabilizing the $\mathrm{Hb}$ molecule while also optimizing its functionality. The two main approaches developed so far involve the chemical modification of $\mathrm{Hb}$ or its encapsulation within a protective carrier shell. Scheme 4 shows a time line of the main HBOCs developed so far which will be discussed in the next sections. Both strategies aim at eliminating, or at least minimizing, $\mathrm{Hb}$ 's dissociation and extravasation as well as its rapid clearance by the kidneys. At the same time, extended blood circulation lifetimes should also be achieved. Importantly, $\mathrm{Hb}^{\prime}$ s modification should not compromise its $\mathrm{O}_{2}$ loading-releasing abilities.

The chemical-modification approaches developed so far involve: $\mathrm{Hb}$ cross-linking, polymerization and conjugation to polymers. The different $\mathrm{Hb}$ subunits can be cross-linked intramolecularly while polymerized $\mathrm{Hb}$ can be fabricated by employing bifunctional cross-linking reagents. By using bifunctional crosslinkers, the $\mathrm{Hb}$ molecules are linked to each other increasing the overall molecular size. Chemically-modified HBOCs can also be obtained by conjugation to biocompatible polymers such as poly(ethylene glycol) (PEG) or poly(oxy ethylene).

Encapsulation strategies aim to mimic the in vivo situation, where $\mathrm{Hb}$ is encased in a protective RBC membrane. By entrapping $\mathrm{Hb}$ within a carrier system, $\mathrm{Hb}$ is prevented from dissociation into dimers and monomers but also from extravasation into the subendothelial smooth muscle tissue. Encapsulation also reduces $\mathrm{Hb}$ 's high viscosity and high colloidal osmotic pressure. Additionally, $\mathrm{Hb}$ remains protected from direct contact with other blood components and the surrounding tissues. ${ }^{38,39}$ Furthermore, an encapsulation platform allows for the incorporation of additional active compounds within the same carrier. For example, an antioxidant multi-enzyme system can be incorporated together with $\mathrm{Hb}$ in order to avoid or revert Hb's oxidation into nonfunctional metHb. However, employing an encapsulation platform has the problem of rendering a low $\mathrm{Hb}$ content as compared to the chemically-modified HBOCs which are mainly composed by $\mathrm{Hb} .{ }^{32}$ Additionally, $\mathrm{Hb}$ encapsulating platforms can also impede the diffusion of $\mathrm{O}_{2}$ in and out of the carrier. Encapsulation platforms offer a broad range of different structures and materials and, therefore, they require an exhaustive optimization and characterization. Table 1 depicts the main advantages and drawbacks for the two strategies.
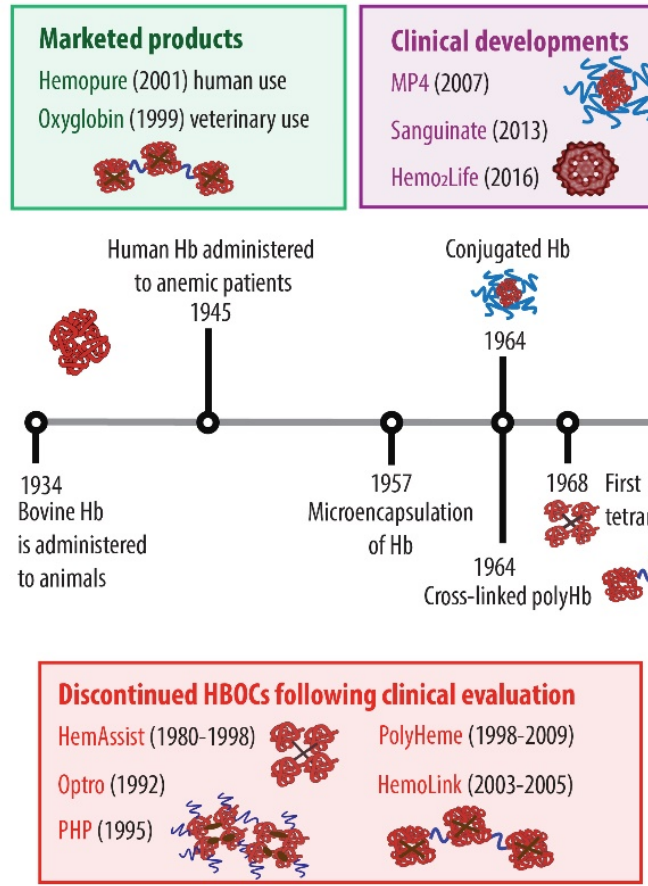
nic patients 945

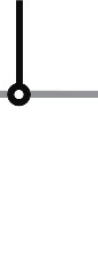

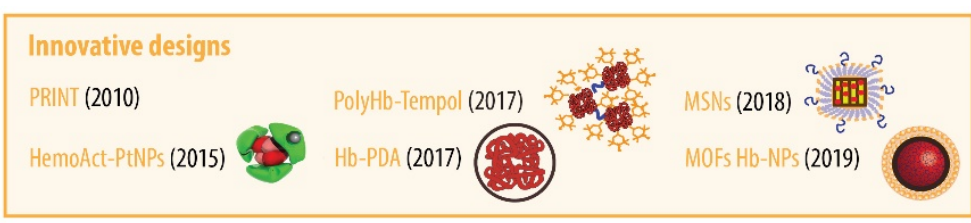
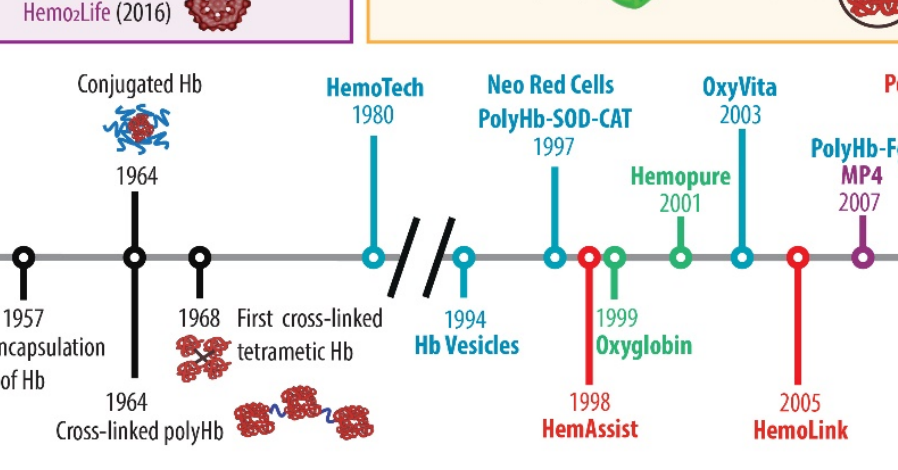

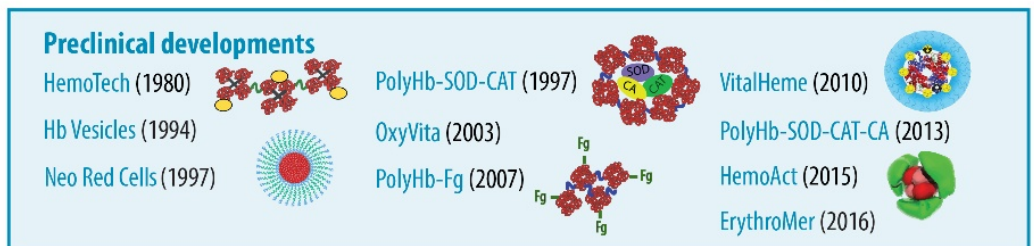

Scheme 4. Time line of the different HBOCs discussed in this review: marketed products showing the date of marketed approval; clinical developments with the date when the clinical trials were started; innovative designs showing the date of the first publication; discontinued HBOCs showing the date of the first publication and when the clinical trials were terminated; and the preclinical developments showing the date when they were first evaluated in in vivo models 


\subsection{Marketed products}

After decades of research and, despite the fact that several products have entered clinical trials, only two HBOCs are currently on the market. This relatively low success is a result of cardiovascular complications and renal dysfunction observed for the treatment groups during clinical trials. ${ }^{40}$ The two approved products are based on chemically-modified HBOCs. While one of them is approved for human use (Hemopure, Biopure Corp., now OPK Biotech, Boston, MA, USA), the other one (Oxyglobin, also from Biopure) has only received veterinary regulatory clearance.

Hemopure. Hemopure $\left(\mathrm{HbO}_{2}\right.$ Therapeutics, USA) is a type of polymerized $\mathrm{Hb}$ (poly $\mathrm{Hb}$ ) created using glutaraldehyde as the bifunctional crosslinking agent. Each poly $\mathrm{Hb}$ is constituted by four or five $\mathrm{Hb}$ molecules yielding a total molecular weight of 250 $\mathrm{kDa}$ and a p50 value of $38 \mathrm{~mm} \mathrm{Hg}$ (Figure 1A). ${ }^{41}$ By increasing the size, extravasation is reduced and the circulatory life increased to over $24 \mathrm{~h}$ (as compared to $6 \mathrm{~h}$ for cell free $\mathrm{Hb}$ ). For this $\mathrm{HBOC}$, bovine $\mathrm{Hb}$ instead of human is used. Making use of bovine $\mathrm{Hb}$ has several advantages since it is widely available and it can be used by certain religious groups refusing donor blood transfusions such as the Jehovah's Witness. ${ }^{42}$ Hemopure was clinically approved in South Africa (in 2001) and in Russia (in 2012) for the treatment of acutely anemic patients. ${ }^{43,44}$ Hemopure clinical trials showed a decreased need for blood transfusions during cardiac surgery however, increased occurrence of cardiac events (i.e., arrhythmia or cardiac infarction), were also observed. As a result, clinical trials with Hemopure were terminated by the Food and Drug Administration (FDA) in 2008. ${ }^{40}$ Nonetheless, since 2013, Hemopure is being administrated also in the USA to patients with life-threatening anemia for whom allogeneic blood transfusion is not an option. ${ }^{28}$ Importantly, within these "compassionate use" programs, survival of the patients is clearly and significantly higher when treated with Hemopure. ${ }^{45}$

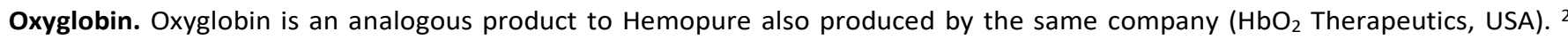
While both products are chemically identical, Hemopure has undergone thorough purification steps to remove the majority of low molecular weight products from the solution. ${ }^{46,47}$ Oxyglobin is currently approved for veterinary use in both the US and the EU. ${ }^{2}$

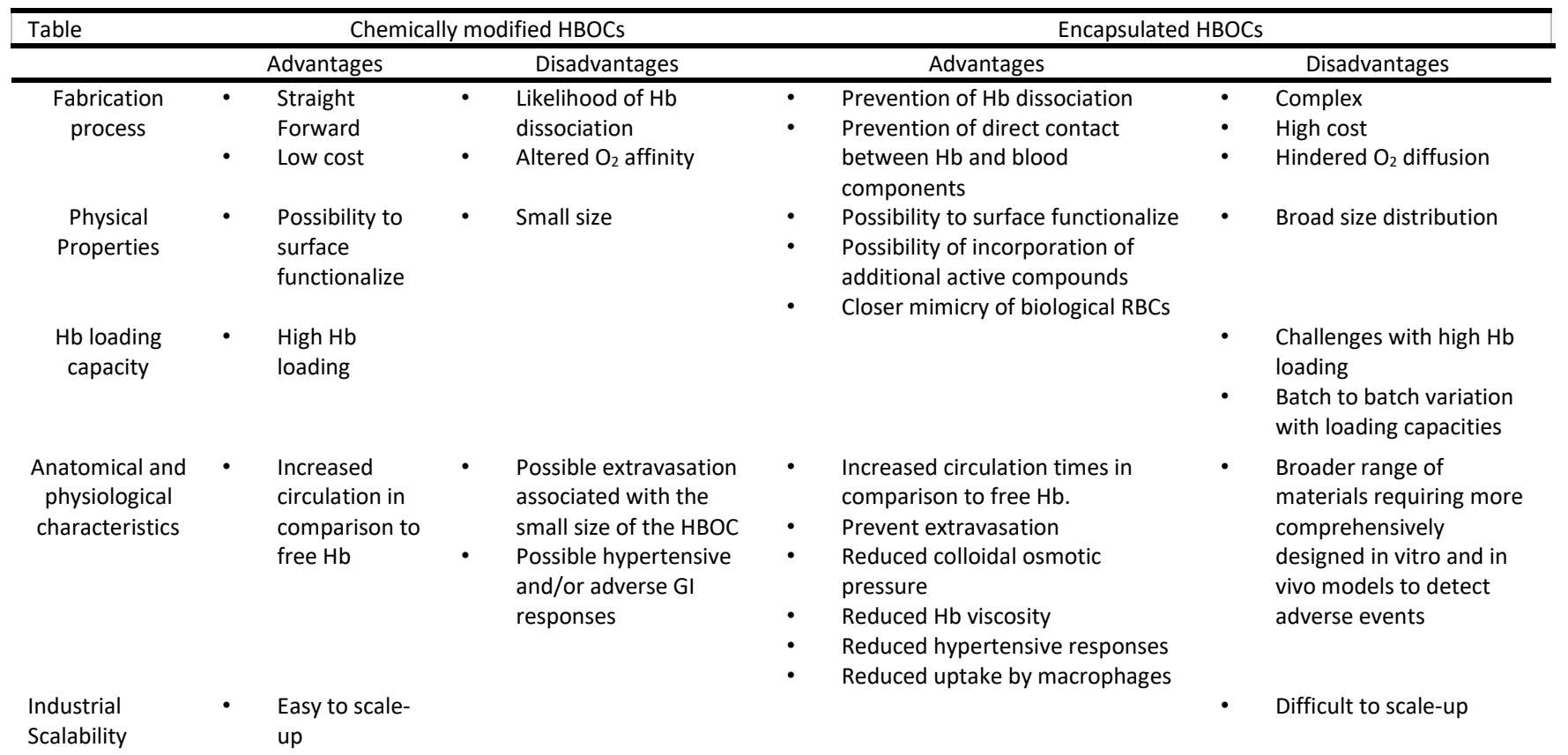

Table 1. The table lists the various advantages and disadvantages of using chemical modification and encapsulation as the strategy for HBOC fabrication 


\subsection{Clinical developments}

MP4 (aka Hemospan). Bioconjugation of $\mathrm{Hb}$ has also been considered as a strategy to increase its stability as well as the in vivo circulation time by reducing immune recognition. ${ }^{48,49}$ PEG is one of the most attractive polymers for bioconjugation due to its biocompatibility and lack of immunogenicity. ${ }^{50}$ Thus, human $\mathrm{Hb}$ has been conjugated to PEG by a maleimide linker. ${ }^{28,51}$ The so called MP4 (previously known as Hemospan, Sangart Inc., San Diego, CA) has a molecular weight of 96 kDa and a p50 value of 6 $\mathrm{mm} \mathrm{Hg.}{ }^{52}$ However, due to a relatively low $\mathrm{Hb}$ content (of $4.2 \mathrm{~g} \mathrm{dL}^{-1}$ ), MP4 is being developed as an oxygen carrier to improve the supply of oxygen rather than a blood surrogate for the full replacement of blood. ${ }^{53}$ Importantly, MP4 did not promote vasoconstriction in animal models and, the clinical trials that have been conducted so far, have shown that MP4 is an efficient oxygen delivery system well tolerated in humans. ${ }^{54,55}$

Interestingly, MP4 is currently also being investigated as a carbon monoxide (CO) carrier (MP4-CO) since CO can also bind to the heme group ( $\mathrm{Hb}-\mathrm{CO}) .{ }^{56}$ While $\mathrm{CO}$ is know as a toxic gas, in very low doses, it acts as a signaling molecule. ${ }^{57}$ Important properties such as anti-inflammatory, antiapoptotic or antiproliferative have been attributed to $\mathrm{CO}$. What is more, CO has the ability to prevent and reverse the polymerization of $\mathrm{Hb} \mathrm{S}$, thus inhibiting the distortion of sickled RBCs. ${ }^{58}$ The potential of MP4-CO in the treatment of sickle cell disease has been demonstrated in a transgenic mouse model, where administration of MP4-CO reduced microvascular stasis after hypoxia or reperfusion. ${ }^{59}$

Sanguinate. PEGylated $\mathrm{Hb}$ has also been employed to develop Sanguinate (Figure 1B). This HBOC has a molecular weight of 120 $\mathrm{kDa}$ and a p50 value of 7-16 mm Hg. Sanguinate also employs $\mathrm{Hb}-\mathrm{CO}$. This CO bound to the $\mathrm{Hb}$ heme group is released within minutes of administration and its thought to avoiding vasoconstriction as a result of its anti-inflammatory properties. ${ }^{60}$ Sanguinate has undergone pre-clinical evaluation in a transfusion rat model where significant reduction of the infarct volume could be observed for the treatment group. ${ }^{61}$ Sanguinate is currently in Phase I and II clinical trials for sickle cell disease and in Phase I for the treatment of acute anemia. Promising results in terms of safety profile and oxygenation parameters are being demonstrated. ${ }^{2,3}$ Sanguinate is also currently available under an emergency investigational new drug protocol where it has enabled the survival of several patients refusing blood transfusion due to religious reasons. ${ }^{60,62,63}$

$\mathrm{Hemo}_{2}$ Life and organ transplantation. Hemo 2 Life is constituted by unmodified cell-free $\mathrm{Hb}$. However, this $\mathrm{HBOC}$ employs $\mathrm{Hb}$ extracted from lugworms, which is not packed within RBCs or any other type of membrane (Figure $1 \mathrm{C}$ ). This lugworm $\mathrm{Hb}$ has a molecular weight of $3600 \mathrm{kDa}$ and a p50 value of $7 \mathrm{~mm} \mathrm{Hg}$. As a result of its large size, each $\mathrm{Hb}$ can transport $38 \times \mathrm{more}_{2} \mathrm{molecules}$ than mammal $\mathrm{Hb}$. Additionally, Hemo 2 Life displays intrinsic SOD-like activity thus having the ability to deplete ROS. ${ }^{64}$ Interestingly, $\mathrm{Hemo}_{2}$ Life has been evaluated both in pre-clinical animal models and clinical trials but in the context of organ transplantation. As a result of the mismatch between the demand and the supply of viable transplantable organs, research efforts have been focusing on developing solutions for organ preservation and extracorporeal resuscitation. Prolonged periods of ischemia are inherent to harvesting and transplanting donor organs thus resulting in ischemia-reperfusion injuries. ${ }^{65}$ This, in turn, enhances the risk of early-graft dysfunction and reduced long-term survival. Current standard preservation techniques include hypothermic storage in a preservation fluid containing electrolytes, amino acids and other compounds designed to preserve cell integrity. However, the lack of oxygen results in the depletion of adenosine triphosphate (ATP) and the building-up of toxic substances within the cells (i.e., adenosine, inosine and hypoxantine). ${ }^{10,65}$ As a result of ATP depletion, a large number of cellular processes are disrupted. ${ }^{66}$ Additionally, the inactivation of the sodium and potassium ATPase pumps results in the accumulation of calcium, sodium and water promoting cellular swelling. ${ }^{67}$ Such an anaerobic metabolism promotes the decrease of intracellular $\mathrm{pH}$ which, in turn, causes in lysosomal instability with the subsequent activation of lytic enzymes causing cellular damage. All in all, this cellular malfunction resulting from prolonged organ preservation, can lead to the failure of the graft. ${ }^{10,65}$ Thus, the development of artificial oxygen carriers hold a lot of potential to create novel preservation solutions in the context of organ transplantation. In this context, $\mathrm{Hemo}_{2} \mathrm{Life}$ is one of the most advanced artificial oxygen carriers for organ transplantation purposes. Pre-clinical evaluation in animal models have demonstrated the ability of Hemo 2 Life to improve the storage of donor rat hearts and pig lungs. 68,69 transplantation. Additionally, Phase I clinical trials of kidney transplantation, have confirmed the safety of Hemo ${ }_{2}$ Life for both patients and grafts (Figure $1 \mathrm{C}$ ). ${ }^{28}$ Importantly, significantly less delayed graft function and a shorter renal function recovery was observed for the treatment groups. Currently, Phase II and III clinical trials are being conducted. 

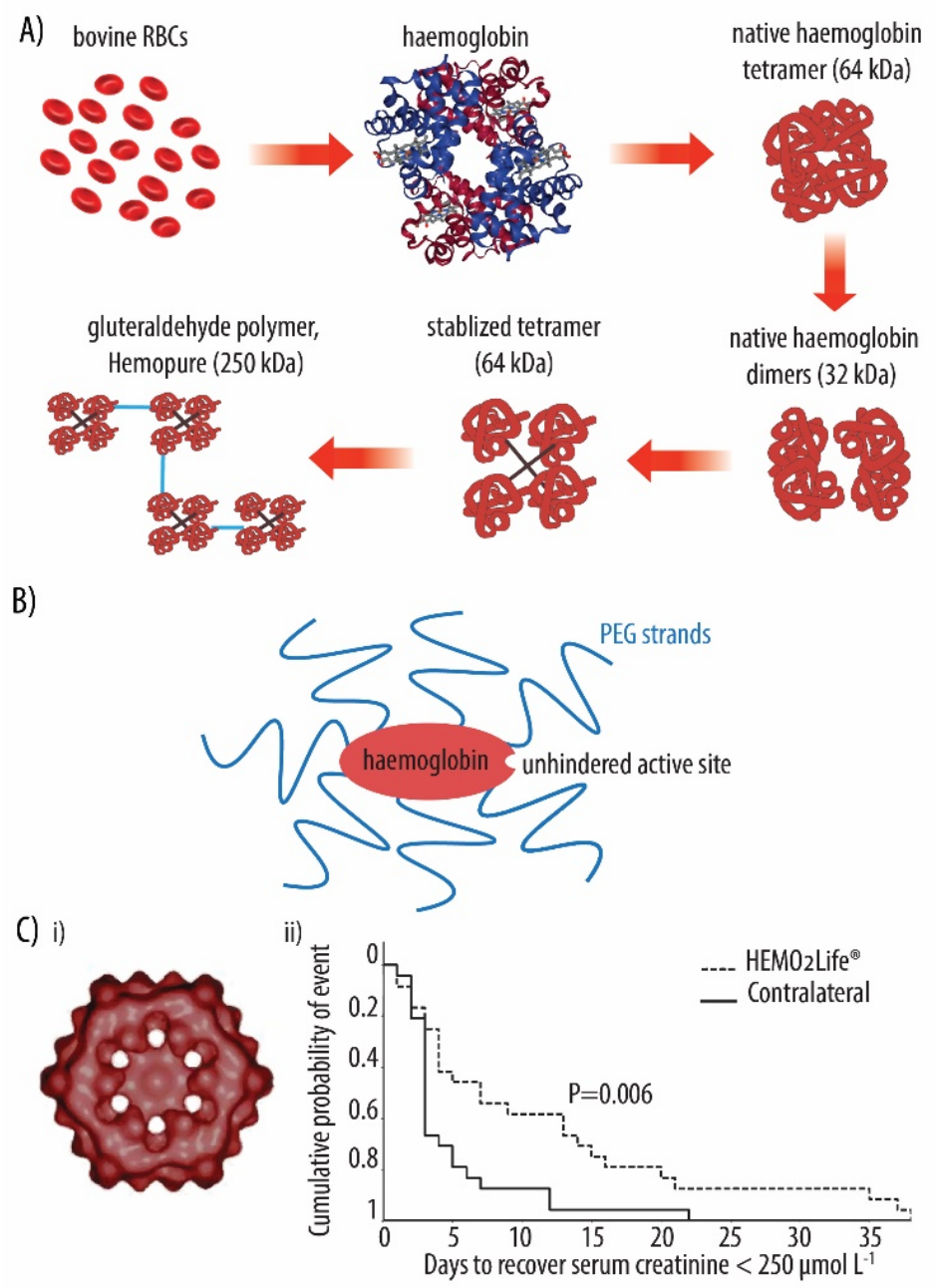

\begin{abstract}
Fig. 1. A) Hemopure development. Haemoglobin is extracted from bovine red blood cells (RBCs). This extracellular tetramer dissociates into its dimers which are crosslinked via glutaraldehyde. Four to five tetramers are crosslinked together rendering Hemopure with a molecular weight of $250 \mathrm{kDa}$. B) Schematic illustration of Sanguinate, which is a poly(ethylene glycol) (PEG)ylated haemoglobin-based oxygen carrier. C) i) Haemoglobin M101 extracted from lugworm, Arenicola marina which is used for the production of $\mathrm{HEMO}_{2} \mathrm{Life}^{\circledast}$. This oxygen carrier is used to oxygenate tissues prior to organ transplantation. li) Kaplan-Meier estimate curves of cumulative probability to achieve creatinine levels below $250 \mu \mathrm{mol} \mathrm{\textrm {L } ^ { - 1 }}$ of two groups of 25 paired kidneys preserved in cold storage in the presence or absence (contralateral) of $\mathrm{HEMO}_{2} \mathrm{Life}^{\oplus}$. There was a significant difference in time to achieve the event between the two groups. Adapted with permission from ${ }^{146}$. Copyright 2020 The American Society of Transplantation and the American Society of Transplant Surgeons.
\end{abstract}

The $\mathbf{2 0 0 8}$ meta-analysis and the need of incorporating antioxidant functions. Research in blood surrogates spans several decades. In fact, major interest in developing synthetic $\mathrm{O}_{2}$ carriers took place in the 1980 s, due to the fear to contaminated blood products owing to the HIV crisis. However, despite the efforts, no product is currently clinically approved for human use neither in the USA nor in Europe. Only Hemopure has been approved in South Africa and Russia for human use and, under special circumstances, it may be administered for compassionate use in the USA and Europe. ${ }^{2}$ This limited success is partly a result of a meta-analysis of 16 clinical trials for five different HBOCs that were seeking FDA approval. Such meta-analysis, which was conducted in 2008, indicated increased risk of myocardial infarction and death in the treatment groups. ${ }^{40}$ Although this study was statistically well executed, it has received much criticism in terms of the analysis design. ${ }^{70}$ While the pre-clinical animal studies of the different HBOCs had been conducted in healthy, normal young animals; many of the clinical trials involved populations with elderly, diabetic, atherosclerotic and hypertensive patients. ${ }^{71}$ Thus, much of the criticism was directed to the fact that the meta-study did not take into account the 
patients pre-existing conditions since, actually, many of the discontinued products did well in healthy patients that underwent elective surgery. ${ }^{15}$ Additionally, a prominent feature of the treatment groups with pre-existing conditions, is the presence of endothelial dysfunction, including impaired NO response and exaggerated endothelin response. ${ }^{70}$ Thus, the administration of HBOCs with undesirable NO scavenging ability could have exacerbated rather than corrected these pre-existing conditions. As such, this meta-analysis emphasized the need for a better understanding of the benefits and drawbacks of the different HBOCs both at fundamental physiological and mechanistic levels. ${ }^{2}$ As a result of the research conducted in recent years, it is now widely accepted that, the cardiovascular complications of the clinical trials, were a result of the NO scavenging abilities of $\mathrm{Hb}$, hememediated oxidative side reactions as well as to the $\mathrm{O}_{2}$ over supply. ${ }^{72}$ This fact would explain the differences observed between the pre-clinical studies conducted in healthy animals and the clinical studies.

Below we comment on the different HBOCs that have been discontinued following clinical evaluation.

Discontinued HBOCs Following Clinical Evaluation. HemAssist. HemAssist (Baxter, USA), also known as Diaspirin or DBBF-Hb, consists of intramolecular crosslinked human $\mathrm{Hb}$. Specifically, the lysine groups of the two alpha-subunits of the $\mathrm{Hb}$ tetramer in the deoxy conformation (Lys99 from $\alpha 1$ and Lys99 from $\alpha 2$ ) are crosslinked by acylation using bis-(3,5 dibromosalicyl)-fumarate. ${ }^{73-}$ ${ }^{76}$ Such a product displayed a p50 of $30 \mathrm{~mm} \mathrm{Hg}$ which is very close to the p50 of Hb entrapped within natural RBCs (i.e., P50 of 26 $\mathrm{mm} \mathrm{Hg}$ ). Compared to cell free $\mathrm{Hb}$, HemAssist showed a substantial increase in circulation residence time (i.e., of $12 \mathrm{~h}$ as compared to less than $6 \mathrm{~h}$ for free $\mathrm{Hb}$ ). While HemAssist had been extensively evaluated in preclinical models and also phase I and II clinical studies, phase III clinical trials were discontinued due to a $72 \%$ increase in mortality rate for the treatment groups as compared to the saline control. ${ }^{77,78}$

Optro. Optro (Somatogen, USA) also consists of intramolecular cross-linked $\mathrm{Hb}$. In this product, recombinant $\mathrm{Hb}$ was used. Specifically, the deoxy form of the low oxygen affinity mutant $\mathrm{Hb}$ Presbyterian ( $\beta$ N109K) was expressed in Escherichia Coli.70 Interestingly, the mutations had been incorporated to render a highly-stable $\mathrm{Hb}$ that does not dissociate into $\alpha_{1} \beta_{1}$ dimers under normal physiological conditions. ${ }^{79}$ Furthermore, this recombinant $\mathrm{Hb}$ also displayed reduced NO scavenging ability. ${ }^{79}$ The two alpha-subunits of the tetramer were next crosslinked by glycine. ${ }^{3,80}$ Similarly to HemAssist, Optro displayed a p50 value also close to that of $\mathrm{Hb}$ entrapped within biological RBCs. Phase I and II clinical trials in elective surgeries were conducted and finally discontinued as a result of hypertensive effects. ${ }^{70}$

PolyHeme. PolyHeme (Northfield Laboratories, Evanston, II) is composed by polyHb. As opposed to Hemopure, which is also a polyHb-based product, PolyHeme employs pyridoxylated human $\mathrm{Hb}$ instead of bovine $\mathrm{Hb}$. PolyHeme was evaluated in several cardiac surgery and trauma/emergency clinical trials. ${ }^{77,81}$ However adverse effects were observed and attributed to vasoconstriction and oxidative stress. ${ }^{46}$ As a result, PolyHeme was rejected by the FDA in 2009 and Northfield Laboratories were closed down. ${ }^{10}$

Hemolink. HemoLink (Hemosol Inc, Mississauga, Ontario, Canada) is another type of polyHb. For this product, the raffinose trisaccharide was employed both as an intra- and intermolecular crosslinker. HemoLink displayed a p50 of 38-40 mmHg and a noncooperative behavior as shown by a Hill coefficient of one. ${ }^{70}$ This is opposed to biological RBCs, where Hb displays oxygen-binding cooperativity as shown by the Hill coefficient values in the range of 2.5-2.9. ${ }^{70}$ Phase II clinical trials were conducted in 2003 , where the administered HemoLink demonstrated the ability to reduce the need for a subsequent autologous blood transfusion as compared to the pentastarch control. ${ }^{82}$ However, also with this product, hypertension, myocardial infarction and also gastrointestinal side effects, were observed during the clinical trials resulting in HemoLink being discontinued. ${ }^{10}$

PHP. PHP is a type of pyridoxylated crosslinked and bioconjugated $\mathrm{Hb}$ developed by Apex Bioscience (USA). However, in this case, $\mathrm{Hb}$ is bioconjuagted to poly(oxy ethylene) instead of PEG. PHP was evaluated in clinical trials as an oxygen carrier but also as a NO scavenger to correct hypotensive effects in response to septic shock. ${ }^{83,84}$ However, as a result of several safety concerns, PHP did not received FDA approval and was discontinued.

\subsection{Preclinical developments}

As a result of the failure in clinical trials of the abovementioned HBOCs, research efforts have focused in refining their design to address the toxicity issues. Thus, the following section will focus on novel and advanced HBOCs that have already been evaluated in pre-clinical animal models. The different HBOCs will be classified in two different categories: HBOCs that have been prepared employing either a chemical modification approach or an encapsulation strategy.

Chemically-modified HBOCs. OxyVita. OxyVita consists of inter- and intra-molecularly crosslinked bovine $\mathrm{Hb}$ but, in this case, carbodiimide chemistry is used instead of crosslinkers. ${ }^{28}$ Thus, the $\mathrm{Hb}$ tetramers are linked to each other by amide bonds rendering a $\mathrm{Hb}$ macropolymer with a very low oncotic pressure. Also as a result of its large molecular weight ( 17.000 KDa), extravasation into the smooth muscle tissue following intravenous administration is prevented. ${ }^{85}$ Studies in mice have shown how OxyVita can 
deliver $\mathrm{O}_{2}$ to ischemic tissues more efficiently than biological RBCs. Specifically, diminished damage was observed when OxyVita was used to savage ischemic brain tissue in stroke mice models as compared to biological RBCs. ${ }^{86}$ OxyVita has also been evaluated in a rat hemorrhagic shock set-up mimicking the initial medical treatment of severely injured patients prior arriving to the hospital. ${ }^{53}$ In this context, OxyVita was able to prolong the rats survival for at least three hours employing relatively small volumes of resuscitation fluid. ${ }^{87} \mathrm{It}$ is also worth noticing that OxyVita has also demonstrated to be stable at all ambient temperatures, while also being able to be stored in its lyophilized form at any temperature for at least 5 years. Additionally, OxyVita also has a shelf life of up to twelve months at room temperature in liquid form. ${ }^{53}$

HemoTech. HemoTech is a novel type of bovine polyHb. The novelty of this product lies in co-polymerizing $\mathrm{Hb}$ together with pharmacologically active compounds. In particular, the Hb molecules are linked to ATP, adenosine and GSH. While GSH was incorporated to protect the heme group from NO and ROS, open ring ATP was introduced to regulate the vascular tone through purinergic receptors. Open ring adenosine was incorporated to counteract the potential vasoconstriction promoted by $\mathrm{Hb}$, since adenosine stimulates the adenosine receptors which result in vasodilation, moderate inflammatory reactions and prevention of platelet aggregation. HemoTech has a molecular weight below $500 \mathrm{kDa}$, a p50 of $20 \mathrm{~mm} \mathrm{Hg}$ and Hill coefficient of 1.8. Pre-clinical studies in several animal models have shown the ability of HemoTech to reduce vasoconstriction following a hemorrhage. Additionally, after administration, no adverse nephrotoxic, neurotoxic, oxidative or inflammatory reactions could be detected. 88,89 Early-phase clinical studies have been conducted in the Democratic Republic of Congo, where it has been shown that HemoTech is an efficient oxygen carrier for the treatment of sickle cell diseases, acute and chronic anemia, coronary artery disease, traumatic brain injury and stroke. ${ }^{3}$

VitalHeme. VitalHeme (Synzyme Technologiea LLC, Irvine, California, USA) consists of carboxylated PEG-Hb containing nitroxide moieties (Figure 2Ai). Such a polynitroxylated PEG-Hb (PNPH) displays both SOD- and CAT-like activity. Thus, VitalHeme has the potential to reduce oxidative stress and to decrease the ROS-mediated cytotoxicity of free Hb. Additionally, the PEG side chains provide a "hydrating shell" with a marked oncotic effect that is useful in resuscitation. ${ }^{90}$ The pre-clinical studies have shown the ability of VitalHeme to provide neurovascular protection in a mice model reproducing pre-hospital resuscitation of traumatic brain injury together with hemorrhagic shock (Figure 2Aii). ${ }^{91}$ Neurotoxicity studies were also conducted in vitro, demonstrating preservation of cell viability only for the PNPH group (Figure 2Aiii).

HemoAct. HemoAct is an innovative approach where human serum albumin (HSA) is conjugated to human $\mathrm{Hb}$. Such a conjugation is conducted by covalently reacting $\mathrm{Hb}$ 's surface lysines with HSA's cysteine- 34 using $\alpha$-succinimidyl- $\varepsilon$-maleimide as a cross-linker. ${ }^{92}$ By doing so, a cluster constituted by a $\mathrm{Hb}$ tetramer wrapped around by two or three $\mathrm{HSA}$ molecules $\left(\mathrm{Hb}-\mathrm{HSA} \mathrm{A}_{2}\right.$ and $\left.\mathrm{Hb}-\mathrm{HSA} \mathrm{A}_{3}\right)$ is obtained (Figure 2Bi). Pre-clinical evaluation of HemoAct showed a circulation life-time of 18.5 hours in rats (Figure $2 \mathrm{Bii}$ and iii). Histopathologic evaluation indicated absence of organ damage 7 days post-administration. ${ }^{93}$ However, their ability as an $\mathrm{O}_{2}$ carrier in animal models still remains to be demonstrated.

PolyHb and antioxidant enzymes. Worth mentioning in this context is the work by Chang et al. ${ }^{94,95}$ As early as in 1998 , the authors cross-linked the CAT and SOD enzymes to polyHb. The resulting polyHb-SOD-CAT could be successfully freeze-dried, sterilized and stored at ambient temperature for 320 days. Furthermore, it also displayed antioxidant properties. Pre-clinical evaluation was also conducted on a rat model of intestinal ischemia-reperfusion injury, which demonstrated that polyHb-SOD-CAT decreased the formation of oxygen radicals as compared to polyHb only. In follow up work, the same group incorporated the CA enzyme into the formulation to create polyHb-SOD-CAT-CA. ${ }^{96}$ Such a $\mathrm{HBOC}$ was not only able to carry $\mathrm{O}_{2}$ but also $\mathrm{CO}_{2}$, since it had the ability to lower the tissue $\mathrm{PCO}_{2}$ in a haemorrhagic shock rat model. ${ }^{97}$

The Chang group also pioneered the fabrication of an $\mathrm{O}_{2}$ carrier also displaying platelet-like activity. ${ }^{98}$ By crosslinking fibrinogen (Fg) to $\mathrm{Hb}$, the poly Hb-Fg complex was obtained. The in vitro characterization showed how polyHb-Fg yielded clotting times similar to those of whole blood. In contrast, polyHb alone, showed significantly higher clotting times. The in vivo evaluation also gave very encouraging results since, in an exchange transfusion rat model, polyHb-Fg also showed a clotting time of 1-2 min, which is very similar to that of whole blood. However, the clotting time for polyHb was very high (of about $10 \mathrm{~min}$ ). 


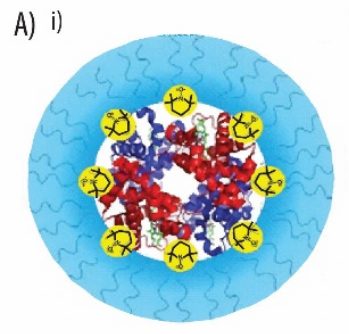

B) i)

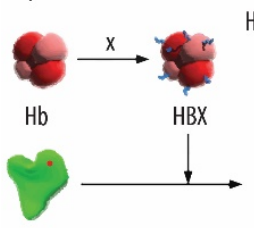

HSA

iii)

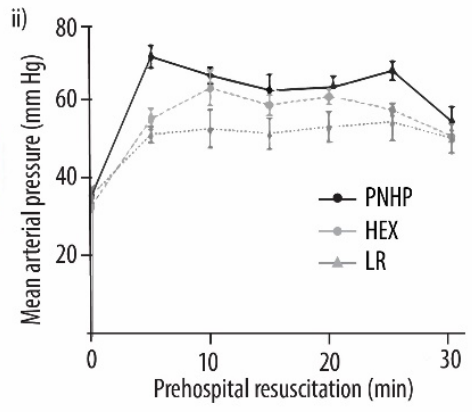

ii)
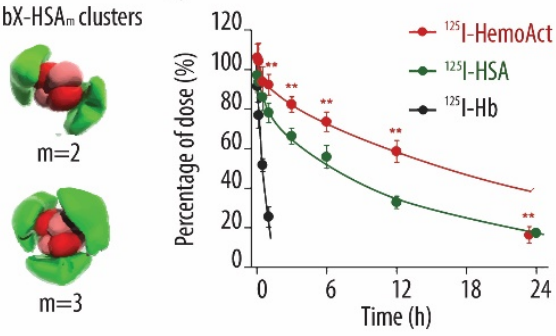

\begin{tabular}{|l|c|c|c|c|c|}
\hline & $\mathrm{t}_{1 / 2}(\mathrm{~h})$ & MRT $(\mathrm{h})$ & $\mathrm{CL}_{\text {lotal }}\left(\mathrm{mL} \mathrm{h}^{-1}\right)$ & $\mathrm{V}_{\text {dss }}(\mathrm{mL})$ & $\begin{array}{c}\text { AUC } \\
\left(\% \text { of dose } \mathrm{mL}^{-1} \mathrm{~h}^{-1}\right)\end{array}$ \\
\hline${ }^{125} \mathrm{I}-\mathrm{Hb}$ & $0.53 \pm 0.1$ & $0.74 \pm 0.14$ & $16.5 \pm 2.4$ & $12.0 \pm 1.3$ & $6.2 \pm 0.9$ \\
${ }^{125} \mathrm{I}-\mathrm{HSA}$ & $11.0 \pm 0.67$ & $15.0 \pm 0.88$ & $0.95 \pm 0.07$ & $14.3 \pm 1.4$ & $105.5 \pm 8.2$ \\
${ }^{125}$ I-HemoAct & $18.5 \pm 1.7$ & $26.3 \pm 2.5$ & $0.50 \pm 0.07$ & $13.0 \pm 0.74$ & $203.4 \pm 23.2$ \\
\hline
\end{tabular}

Fig. 2. A) i) Schematic of polynitroxylated poly(ethylene glycol) (PEG)-ylated haemoglobin (PNPH). A haemoglobin molecule is functionalised with nitroxides (12-14 per molecule) and PEG chains of about 8-10 5kD forming an outer shell. The resulting PNPH has a molecular radius of approximately $6.8 \mathrm{~nm}$ and a molecular weight of $256 \mathrm{kDa}$. Adapted with permission from ${ }^{90}$. Copyright 2012 John Wiley and Sons. ii) Mean arterial pressure readings over time depending on the administered resuscitation fluid: PNPH, Hextend (HEX) and Lactated Ringer's (LR). HEX (solution of colloids) and LR (isotonic fluid) correspond to the resuscitation fluids used in the civilian and military standards of care, respectively. The time points of 0 and $30 \mathrm{~min}$ correspond to experiment times of 90 and $120 \mathrm{~min}$, respectively. Data indicate mean $+/$ - SEM at each time point, $n=5$ per group $(* p<0.05$, analysis of variance). Adapted with permission from ${ }^{91}$. Copyright 2011 by the Society of Critical Care Medicine and Lippincott Williams \& Wilkins. B) i) Schematic illustration of the synthetic route to create clusters of $\mathrm{Hb}$ and human serum albumin $\left(\mathrm{HbX}-\mathrm{HSA} \mathrm{A}_{m}\right)$ using heterobifunctional cross-linkers (X) Adapted with permission from ${ }^{92}$. Copyright 2013 American Chemical Society. ii) Relative plasma concentration of radiolabelled $\mathrm{Hb}-\mathrm{HSA}_{3}$ cluster (125I-HemoAct), ${ }^{125} \mathrm{I}-\mathrm{HSA}$ and ${ }^{125} \mathrm{I}-\mathrm{Hb}$ at 3, 10, $30 \mathrm{~min}$ and 1, 3, 6, 12 and $24 \mathrm{~h}$ after the infusion in Wistar rats. Each data point represents the mean $\pm \mathrm{SD}(n=6) .{ }^{* *} p<0.01$ vs. ${ }^{125}$ HSA. iii) Different pharmacokinetic parameters following intravenous administration of ${ }^{125}$ HemoAct, ${ }^{125} \mathrm{I}-\mathrm{HSA}$ and ${ }^{125} \mathrm{I}-\mathrm{Hb}$ in Wistar rats. Half-life $\left(\mathrm{t}_{1 / 2}\right)$; mean residence time (MRT);, clearance $\left(\mathrm{CL}_{\text {total }}\right)$; volume of distribution at steady state $\left(V_{\mathrm{dss}}\right)$; area under the curve (AUC). Each value represents the mean \pm SD $(n=6) .{ }^{* *} p<0.01$ vs. ${ }^{125} \mathrm{I}-\mathrm{HSA}$. Adapted with permission from ${ }^{93}$. Copyright 2015 Springer Nature open access.

Encapsulation Strategies. Hb entrapment within micro- or nano-sized (up to $500 \mathrm{~nm}$ ) encapsulation platforms has emerged as a promising strategy. $\mathrm{Hb}$ encapsulation offers several advantages. Firstly, it mimics more closely the physiological encapsulated state of $\mathrm{Hb}$ within biological RBCs. Secondly, by protecting $\mathrm{Hb}$ from being in direct contact with plasma, increased circulation times, reduced hypertensive response and uptake by the mononuclear phagocyte system (MPS) can be achieved. Lastly, encapsulation platforms offer the possibility to incorporate other functional compounds such as antioxidant enzymes or allosteric effector molecules within the same carrier. In fact, the concept of $\mathrm{Hb}$ encapsulation was presented in the 1950s and 1960s in a pioneering work by Chang and collaborators. ${ }^{2}$ The authors were able to encapsulate, not only $\mathrm{Hb}$, but also reductive enzymes within a polymeric micron-sized carrier shell. While, on a first study, cellulose nitrate was used to fabricate the carrier shell, in follow up work, PEG-poly(Lactide) was used as a 
biocompatible and biodegradable material. ${ }^{99,100}$ With such a carrier, the authors were also able to co-encapsulate not only SOD, CAT and CA enzymes but also the 2,3-DPG allosteric effector. ${ }^{101,102}$ However, these Hb-loaded microcarriers, which were termed "hemoglobin corpuscles", were rapidly removed from the circulation by the MPS. Regrettably, reducing the size of the microcarriers to about $1 \mu \mathrm{m}$ in diameter resulted in only a slight improvement on the vascular residence time. ${ }^{2}$

Since then, much work has been conducted towards improving the circulation lifetime by making use of different polymers, phospholipids or surface coatings and below we comment on the few systems that have undergone pre-clinical evaluation.

ErythroMer. Human $\mathrm{Hb}$ has also been encapsulated together with the reductant leuko-methyleneblue and a pH sensitive allosteric effector. The so-called ErythroMer (KaloCyte, St. Louis MO, USA) consists of toroidal-shaped nanoparticles of about $200 \mathrm{~nm}$ in diameter. Such nanoparticles, which are also known as nanobialys, are fabricated by the self-assembly of an amphiphilic polymeric system of polyethylene imine (PEI) grafted to palmitic acid. Leuko-methylene blue encapsulation provides a reductive environment able to retard the rate of metHb conversion. The $\mathrm{pH}$-sensitive allosteric modifier 2-[4-[[(3,5-dimethylanilino) carbonyl]methyl]phenoxy]-2-methylpropionic acid (also known as RSR-13) was incorporated too. RSR-13 promotes the $\mathrm{O}_{2}$ release of $\mathrm{Hb}$ at lower $\mathrm{pH}$, thus increasing $\mathrm{O}_{2}$ availability to hypoxic tissues. ${ }^{103}$

ErythroMer has been evaluated in murine models of hemorrhagic shock and in a hemodilution model of $70 \%$ blood exchange. The results have shown promising oxygen transport in vivo. ${ }^{28,104}$ Additionally, ErythroMer can be efficiently lyophilized and reconstituted in saline prior administration. Despite the progress, biocompatibility, vascular residence time and immunotoxicity still need to be thoroughly evaluated.

$\mathrm{Hb}$ Vesicles. Liposome encapsulated $\mathrm{Hb}$, also known as $\mathrm{Hb}$ vesicles ( $\mathrm{HbVs}$ ), are structures with a core of concentrated $\mathrm{Hb}$ wrapped in a phospholipid membrane (Figure 3A). ${ }^{38}$ The optimized formulation employs dioctadecadienoyl-sn-glycero-3phosphatidylcholine (DODPC) as the main phospholipid for their preparation. Importantly, by $\gamma$-irradiation-induced radiolysis of water molecules within the vesicles, $\mathrm{OH}^{-} \cdot$ lons are generated. Such radicals promote the intermolecular polymerization of the dienoyl groups of the DODPC, which results in highly stable HbVs. Thus, HbVs can be successfully freeze-thawed, freeze-dried and reconstituted in saline. ${ }^{2,38}$ The optimal $\mathrm{HbV}$ formulation has been functionalized by $5 \mathrm{kDa}$ PEG in order to reduce opsonization and the subsequent elimination by the MPS. PEG modification has rendered HbVs with extended circulation times of about $60 \mathrm{~h}$ in some animal models. ${ }^{105-107}$

$\mathrm{HbVs}$ have a size of 250-280 nm in diameter and a p50 ranging from 9 to $30 \mathrm{~mm} \mathrm{Hg}$, which can be adjusted by the co-encapsulation of pyridoxalphosphate. ${ }^{108}$ Each HbV contains about $30.000 \mathrm{Hb}$ molecules with a $30 \%$ encapsulation efficiency. HbVs have similar ODCs and release kinetics than biological RBCs. Additionally, $\mathrm{Hb}$ encapsulation within the vesicles results in reduced NO scavenging due to the extra surface lipid bilayer. The large size of the vesicles as compared to cell-free Hb, avoids Hb's glomerular clearance thus reducing the subsequent nephrotoxicity. HbVs have been extensively studied in pre-clinical animal models. Specifically, their potential as oxygen therapeutics has been evaluated in animal models of haemorrhagic shock or for the oxygenation of ischemic tissues (Figure 3B). ${ }^{107,109}$ Additionally, HbVs have also been evaluated in the context of organ perfusion, extracorporeal membrane oxygenation priming or to provide oxygen in in vitro models of two-dimensional cell cultures. ${ }^{108,110}$ Despite the promising results as therapeutic $\mathrm{O}_{2}$ carriers, issues with pharmacokinetics and complement-mediated immune responses still need to be addressed. ${ }^{38}$ Other important drawbacks of this technology is their broad size distribution and the batch-to-batch variation in $\mathrm{Hb}$ encapsulation efficiencies.

Other Encapsulation Platforms. Other types of vesicles constituted by different phospholipids than DODPC have also been evaluated. ${ }^{111}$ For example, $\mathrm{Hb}$ has been encapsulated within phosphatidylcholine and cholesterol-based vesicles also functionalized by a PEG coating. The resulting $\mathrm{Hb}$-loaded vesicles have been evaluated in hemodiluted beagle dogs where whole blood had been replaced by iso-oncotic starch. Importantly, the animals in the vesicles group survived significantly longer after completion of the treatment as compared to the control group that received saline only. ${ }^{112}$ Other liposome-encapsulated Hbs known as "neo red cells" and "neohemocytes" have been developed and evaluated in vivo. In particular, the neo red cells showed enhanced $\mathrm{O}_{2}$ delivery capacity as compared to natural RBCs in total cardiopulmonary bypass in an animal study. ${ }^{113}$ In another study, $\mathrm{Hb}$ was encapsulated together with enzymes extracted from outdated human RBCs within neo red cells. ${ }^{114}$ The allosteric effector inositol hexaphosphate, the NAD co-enzyme and the required substrates for the enzymes (i.e., adenine and inosine) were also co-encapsulated. In vitro evaluation showed that metHb formation was reduced from $1 \% \mathrm{~h}^{-1}$ to $0.4 \% \mathrm{~h}^{-1}$ upon incorporation of the enzymatic reduction system. These enzyme-loaded neo red cells were also assessed as a perfusate for cardiopulmonary bypass during hypothermia. This was done employing an in vitro artificial lung system where the $\mathrm{O}_{2}$ transporting efficiency could be demonstrated.

There are other $\mathrm{Hb}$ encapsulation platforms that have been fabricated to serve as $\mathrm{O}_{2}$ carriers however, due to early developments, a pre-clinical evaluation still remains to be conducted. For instance, $\mathrm{Hb}$ has also been encapsulated with polymersomes. Polymersomes are the polymeric analogues of lipidic vesicles, fabricated by the self-assembly of amphiphilic block-copolymers. Advantages of polymersomes over liposomes include higher stability both in storage and in vivo. ${ }^{115}$ Their size and thickness can be easily tailored by the right choice of the constituting amphiphilic polymers. Polymersomes can also be produced in large quantities 
A)

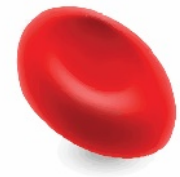

Hb purification

Pasteurization

Nanofiltration

$\mathrm{RBC}(8 \mu \mathrm{m})$

B)

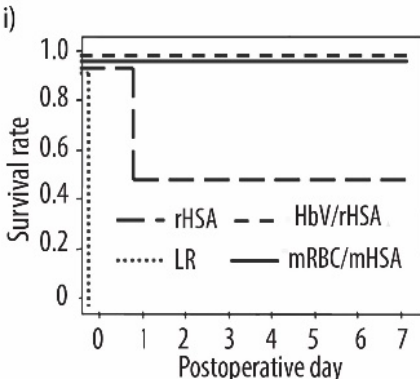

iii)

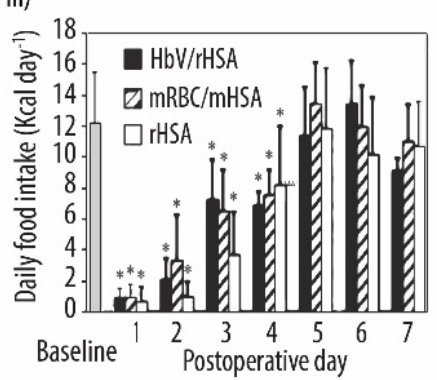

Liposomeencapsulation

Gas exchange $\mathrm{HbCO}(7 \mathrm{~nm})$ No pathogen No blood type
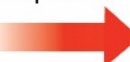
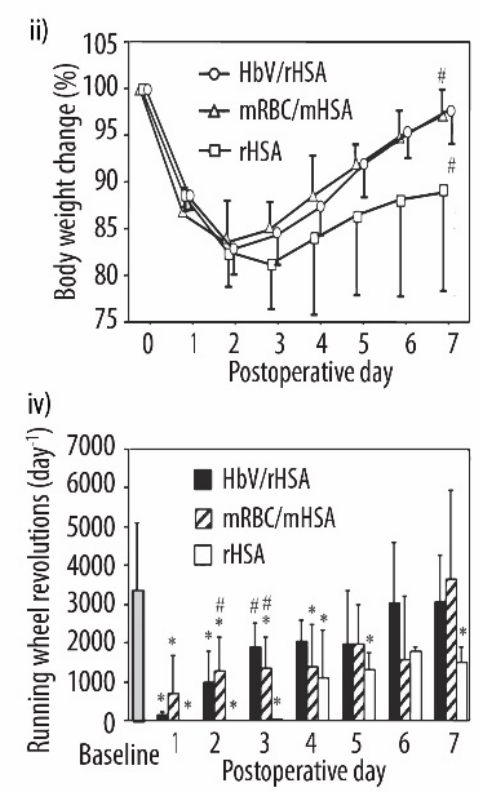

Fig. 3. A) Schematic illustration of the preparation of haemoglobin $(\mathrm{Hb})$-loaded vesicles (HbV). $\mathrm{Hb}$ is extracted from outdated nucleic acid amplification testing-inspected red blood cells (RBCs) provided by the Japanese Red Cross. The concentrated carbonyl haemoglobin ( $\mathrm{HbCO}$ ) is purified by pasteurization and nanofiltration for utmost safety from infection. Adapted with permission from ${ }^{108}$. Copyright 2017 MDPI. B) In vivo evaluation of HbV. Survival rate (i), change in body weight (ii), daily food intake (iii) and running wheel revolutions (iv) for mice undergoing a $40 \%$ blood exchange with: $\mathrm{HbV}$ and recombinant human serum albumin ( $\mathrm{rHSA})(\mathrm{HbV} / \mathrm{rHSA})$; mouse RBCs (mRBCs) and rHSA (mRBC/rHSA) or Lactated Ringer's (LR). The results show differences in survival rate, $n=10$, (i) percent change in body weight ( $n=10$ initially in each group, $n=5$ after the $1^{\text {st }}$ postoperative day (POD) in the rHSA group) (ii) daily food intake $(n=10$ initially each group, $\mathrm{n}=5$ after the $1^{\text {st }}$ POD in the rHSA group) (iii) and daily number of running wheel revolutions ( $\mathrm{n}=$ 5 between the baseline period and the $7^{\text {th }}$ POD in the indicated study groups) (iv). Values are shown as the mean \pm SD. ${ }^{*} P<0.05$ versus baseline (Student's t-test), $\# P<0.05$ versus the rHSA group (Dunnett's test). Adapted with permission from ${ }^{110}$. Copyright 2017 PLoS One open access.

and, following $\mathrm{Hb}$ encapsulation, they show similar $\mathrm{O}_{2}$ affinity to human $\mathrm{RBCs}$. Hb-loaded polymersomes are also stable in saline for several months and in blood for at least five days. ${ }^{116,117}$ However, due to a thicker shell as compared to the phospholipidic counterparts, research efforts should focus in evaluating the $\mathrm{O}_{2}$ diffusion in and out of the system. ${ }^{2,3}$ Another encapsulation strategy consists of entrapping $\mathrm{Hb}$ within polymeric micelles. Using this approach, $\mathrm{Hb}$ has been incorporated into the micelles by covalently reacting carbonyl moieties of the polymer with $\mathrm{Hbs}$ amino groups. ${ }^{50} \mathrm{On}$ a different approach, $\mathrm{Hb}$ was incorporated onto the micelle's surface (Figure 4A). ${ }^{118}$ The resulting $\mathrm{Hb}$-loaded micelles had the ability to reversibly bind and release $\mathrm{O}_{2}$ in an in vitro set up (Figure 4B). Additionally, no detrimental effects on blood components could be observed in vitro (Figure 4C). Polymeric particles in the micron range have also been evaluated. For example, by co-precipitating $\mathrm{Hb}$ and calcium carbonate $\left(\mathrm{CaCO}_{3}\right)$, followed by glutaraldehyde cross-linking and $\mathrm{CaCO}_{3}$ dissolution, $\mathrm{Hb}$-loaded microparticles have been prepared. ${ }^{119}$ With a similar approach, $\mathrm{Hb}$ was co-precipitated with $\mathrm{MnCO}_{3}$ followed by the immediate addition of HSA for encapsulation and stabilization of the particles. ${ }^{120}$ Such particles demonstrated reduced vasoconstriction, low immunogenicity and did not interfere with platelet activation. Additionally, they successfully delivered $\mathrm{O}_{2}$ in an in vitro (mouse) afferent arteriole model. While these systems have shown considerable promise toward their application as RBC surrogates employing in vitro models, follow up in vivo evaluation is essential in order to assess their full potential. 

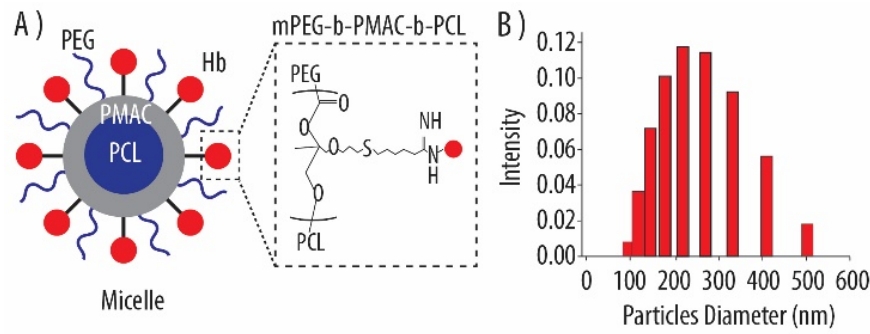

C)

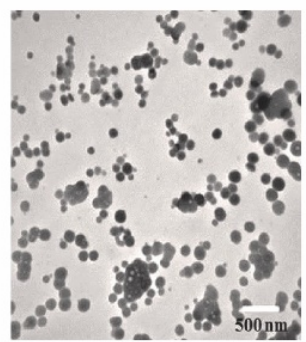

D)

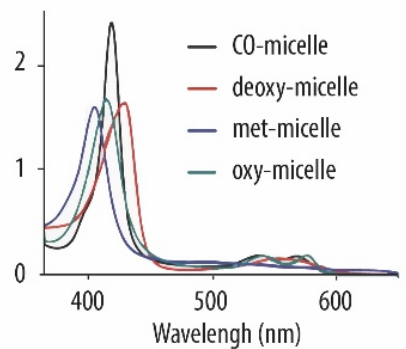

E)

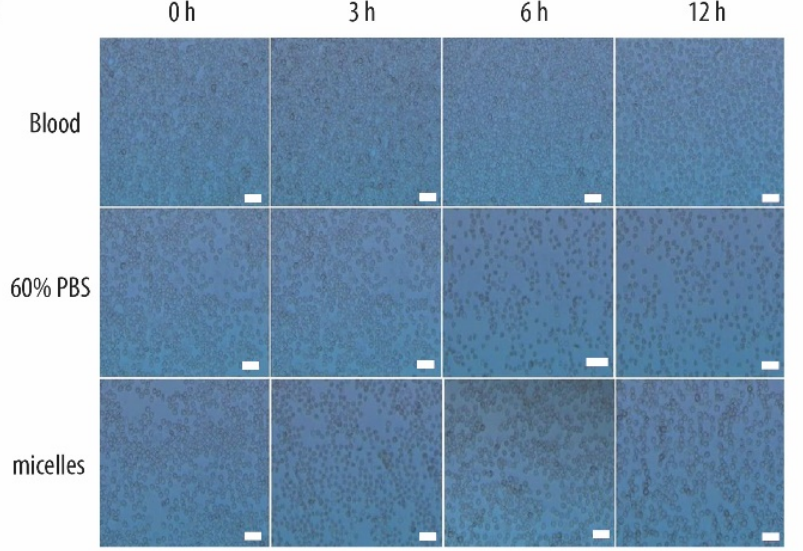

Fig. 4. A) Schematic illustration of polymeric micelles with haemoglobin $(\mathrm{Hb})$ bound onto the surface. The insert shows the chemicals structure of the triblock co-polymer used to assemble the micelles. The polymer mPEG-b-PMAC-b-PCL is constituted by a methoxyl poly(ethylene glycol) (mPEG) block, a 5-methyl-5-acryloyloxymethyl-1, 3-dioxan-2-one (PMAC) block and poly caprolactone (PCL). B) Dynamic light scattering results and $\mathrm{C}$ ) transmission electron microscopy image of the micelles. D) UV-vis spectra of the micelles and free haemoglobin $(\mathrm{Hb})$ in different atmospheres. E) Morphology of RBC mixed with different solutions observed by optical microscopy (bar $=20 \mu \mathrm{m})$. Adapted with permission from ${ }^{118}$. Copyright 2016 John Wiley and Sons.

\subsection{Novel and innovative designs}

Clinical studies of HBOCs have been mainly conducted in the context of trauma or major surgery. Within this framework, HBOCs did not show a general benefit in terms of avoidance or reduction of RBC transfusions or 28-day mortality. ${ }^{121}$ On the contrary, enhanced risk of myocardial infarction and death was observed in the treatment groups. ${ }^{3}$ These adverse effects were attributed to the vasoconstriction resulting from NO scavenging. Due to this toxicity issues, in 2008, all HBOCs were put on hold by the FDA. ${ }^{2}$ However, several lessons have been learned from the failure of this first generation of HBOCs and the new generations of HBOCs are currently minimizing NO binding and heme-mediated side reactions. Additionally, due to the relatively short circulation lifetimes of the reported HBOCs as compared to human RBCs (i.e., of about 120 days) the focus has shifted from "RBCs substitutes" to "oxygen therapeutics". The aim is to highlight the important role of these products in situations where donor blood is not available (e.g., remote locations, emergency in an ambulance, far-forward military settings). Thus, in the following section, we comment on recent and innovative approaches developed to address the aforementioned limitations of the first reported HBOCs. The chosen examples have been thoroughly characterized in vitro in terms of morphology, stability, cytotoxicity and biofunctionality. However, due to early development, pre-clinical evaluation in relevant animal models still remains to be conducted. 
Chemically-modified HBOCs. A novel HBOC with the ability to counteract oxidative stress is composed by polyHb crosslinked to a Tempol compound with an amine group (4-amino-2,2,6,6-tetramethylpiperidine-1-oxyl, $\mathrm{NH}_{2}$-Tempol). ${ }^{122}$ Tempol is a nitroxide compound with the ability to shuttle between the nitroxide radical, the reduced hydroxylamine and the oxidized oxoammonium cation form. Such polyHb-Tempol was able to eliminate $\mathrm{O}_{2}-{ }^{-}$-induced oxidative stress in an endothelial cell in vitro model indicating SOD-like activity. Other antioxidative compounds incorporated to polyHb include ferulic acid (FA) which is able to quench oxygen free radicals. ${ }^{123}$ While FA was successfully incorporated to generate an FA-modified $\mathrm{Hb}$, the antioxidant properties of such a HBOCs still remain to be demonstrated.

On an innovative approach, the HemoAct product consisting of Hb-HSA core-shell nanoclusters was also equipped with antioxidant platinum nanoparticles (PtNPs) (Figure 5A). ${ }^{93}$ The PtNPs were incorporated within the clefts of the HSA units of the clusters where they were acting as reductive catalytic entities and were able to deplete $\mathrm{O}_{2} \cdot-$ radicals and $\mathrm{H}_{2} \mathrm{O}_{2}$ which, in turn, prevented the formation of metHb (Figure $5 \mathrm{~B}$ and $\mathrm{C}$ ).

Another innovative approach, to reduce NO scavenging, the $\mathrm{Hb}$ cysteine residues of $\mathrm{Hb} \beta$-subunits have been $\mathrm{S}$-nitrosilated. The aim was to endow $\mathrm{Hb}$ with NO producing abilities. 124

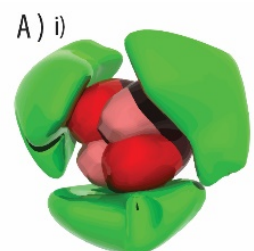

$\mathrm{Hb}-\mathrm{HSA}_{3}$

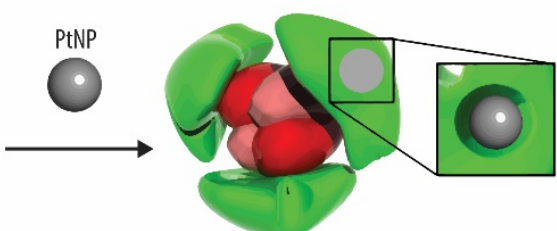

$\mathrm{Hb}-\mathrm{HSA}_{3}$ (PtNP)

iii)<smiles>CCCCCCNC(=O)C1CCC(CN2C(=O)CC(SCC)C2=O)CC1</smiles>

SOD activity

$2 \mathrm{O}_{2}+2 \mathrm{H}^{+} \longrightarrow \mathrm{H}_{2} \mathrm{O}_{2}+\mathrm{O}_{2}$

Catalase activity

$2 \mathrm{H}_{2} \mathrm{O}_{2} \longrightarrow \mathrm{O}_{2}+2 \mathrm{H}_{2} \mathrm{O}$

B)

C)
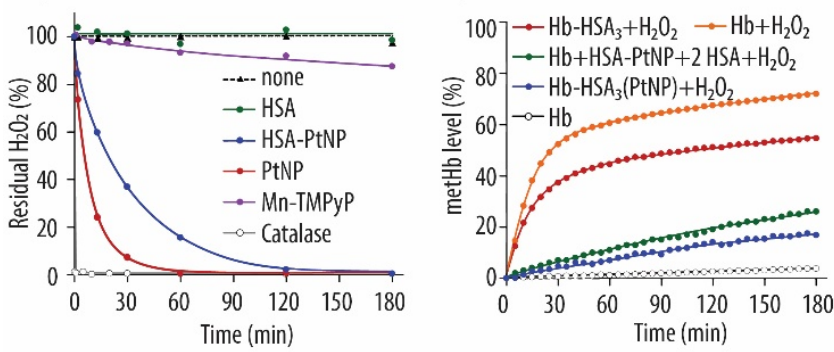

Fig. 5. A) i) Schematic illustration of the $\mathrm{Hb}-\mathrm{HSA}_{3}$ cluster which is constituted by a haemoglobin $(\mathrm{Hb})$ molecule at the centre and three covalently linked human serum albumins (HSA) located at the periphery. The cluster also incorporates platinum nanoparticles (PtNPs) located into the external albumin units yielding an $\mathrm{Hb}$ $\mathrm{HSA}_{3}$ (PtNP) cluster. ii) The thiol residue (Cys-34) of HSA and the surface Lys group of $\mathrm{Hb}$ are covalently connected through a crosslinker. iii) The PtNPs are able to conduct superoxide dismutase (SOD)-like and catalase-like activities. B) Residual hydrogen peroxide $\left(\mathrm{H}_{2} \mathrm{O}_{2}\right)$ over time following incubation with: HSA, a solution of the HSA-PtNP complex, PtNPs, Mn(III)-terakis(N-methylpyridinium) porphyrin (Mn-TMPyP) and the natural catalase enzyme. C) MetHb conversion over time of several Hb-containing solutions in the presence of $\mathrm{H}_{2} \mathrm{O}_{2}$. Adapted with permission from ${ }^{147}$. Copyright 2014 PLoS One open access. 
Encapsulation strategies. Encapsulation strategies have also addressed the challenge of avoiding heme-mediated side reactions by offering antioxidant protection. Specifically, several recent studies have focused in encapsulating $\mathrm{Hb}$ within a polydopamine (PDA) shell. PDA is formed by the self-polymerization of dopamine (DA) at slightly basic conditions and in the presence of $\mathrm{O}_{2}$. PDA can be deposited onto practically any substrate independent of size and shape. ${ }^{125}$ Importantly, PDA has barely any reaction with underlying functional groups, thus preserving $\mathrm{Hb}$ 's structure and functionality. ${ }^{126}$ Additionally, PDA also holds a redox character which has been used to protect $\mathrm{Hb}$ from oxidation into metHb. In particular, Wang et al. coated single $\mathrm{Hb}$ molecules rendering $\mathrm{Hb}$ PDA (Figure 6A and B). ${ }^{126}$ Such a PDA coating was able to inhibit metHb formation as well as heme oxidation to ferryl (Fe ${ }^{4+}$ ) $\mathrm{Hb}$ Additionally, the $\mathrm{Hb}$-PDA particles were able to scavenge free radicals and ROS. They were also able to supress intracellular ROS generated by incubating cardiomyocytes with $\mathrm{H}_{2} \mathrm{O}_{2}$ (Figure 6C). Micron-sized $\mathrm{Hb}$ particles fabricated by co-precipitation have been also successfully coated by PDA. ${ }^{127}$ In this study, the PDA-coated particles showed twice as much functional Hb content than their uncoated counterparts. This was attributed to PDA's antioxidant properties, which minimized metHb conversion. PDA-coated Hb particles fabricated by co-precipitation were also reported by Hu et al. ${ }^{128}$ In this study, the PDA coating minimized Hb leakage from the particles also in flow conditions. Additionally, as a result of the antioxidant PDA coating, the particles were able to reduced oxidative injury in an in vitro model using HUVEC cells. We also recently reported the fabrication of PDA-coated NPs fully made of $\mathrm{Hb}$ employing the electrospray technique. ${ }^{129}$ The ability of the PDA-coating in minimizing metHb conversion was also demonstrated. In this study, the Hb-NPs were further functionalized by a PEG coating and the low-fouling properties of the PEGylated $\mathrm{Hb}-\mathrm{NPs}$ was evaluated in terms of decreased protein adsorption.

A)
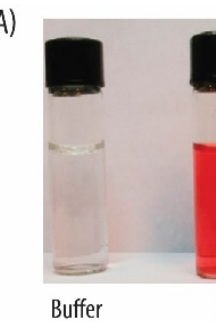

Buffer

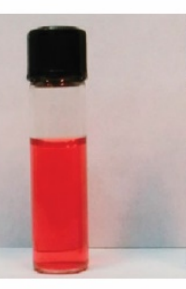

$\mathrm{Hb}$

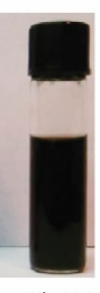

$\mathrm{Hb}-\mathrm{PDA}$

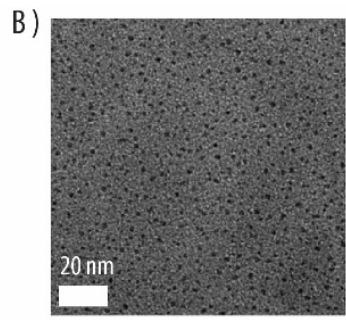

C)

ROS

Bright field
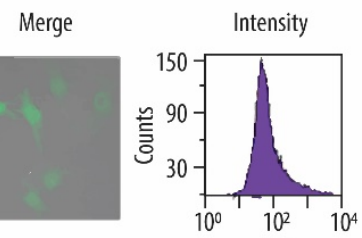

Control

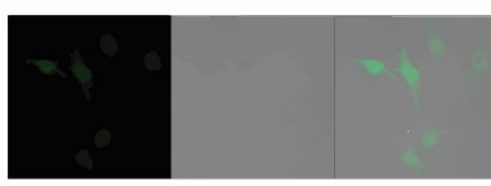

$\mathrm{H}_{2} \mathrm{O}_{2}$
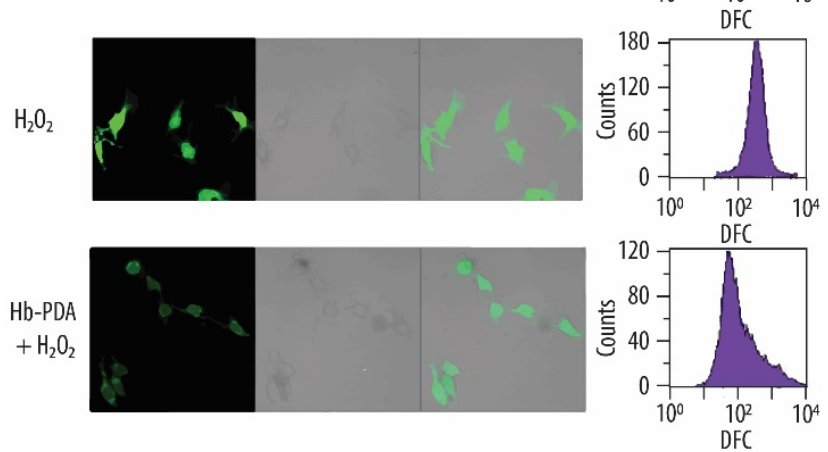

Fig. 6. A) Photographic images of Tris- $\mathrm{HCl}$ buffer, a solution of haemoglobin ( $\mathrm{Hb}$ ) and a suspension of polydopamine (PDA)-coated $\mathrm{Hb}$ (Hb-PDA). B) Transmission electron microscopy images of $\mathrm{Hb}$-PDA. C) Ability of $\mathrm{Hb}$-PDA to scavenge intracellular reactive oxygen species (ROS). Specifically, H9c2 cells were incubated with $\mathrm{Hb}$-PDA for $12 \mathrm{~h}$ at $37{ }^{\circ} \mathrm{C}$ followed by exposure to hydrogen peroxide $\left(\mathrm{H}_{2} \mathrm{O}_{2}\right)$ for $120 \mathrm{~min}$. Then, the cells were observed by confocal microscopy and analysed by flow cytometry making use of the fluorescent probe DCFH-DA. Adapted with permission from ${ }^{126}$. Copyright 2017 American Chemical Society.

Metal-organic frameworks (MOFs) are also an interesting material for the fabrication of HBOCs. MOF are self-assembled structures constituted by metal ions or clusters connected by organic linkers and they display well-defined, crystalline pore structures. ${ }^{130-132}$ Their well-defined cages, which can be adjusted by the right choice of metal ions or clusters and organic linkers, have been used to encapsulate a wide range of biomolecules such as proteins, ${ }^{133}$ enzymes ${ }^{134,135}$ and DNA. ${ }^{136}$ As a result of their high void space and pre-defined cavities, MOF-based NPs have been used for $\mathrm{Hb}$ encapsulation. A first report employed the so-called zeolitic imidazole framework-8 (ZIF-8). ${ }^{137}$ Due to this ZIF-8 coating, the encapsulated Hb exhibited enhanced stability upon exposure to several harsh conditions such as alkaline treatment, oxidation, high temperature or even an enzymatic environment. What is more, 
following evaluation in a murine model, the Hb-loaded ZIF-8 NPs displayed extended circulation times and reduced nonspecific distribution in normal organs as compared to free Hb. The ZIF-8 NPs where also evaluated in a mice model of haemorrhagic shock where enhanced survival time was observed for the treatment group. We also employed MOF-NPs for Hb encapsulation. Specifically, we used the so-called porous coordination network (PCN)-333(Al) which is composed of trivalent metal species (i.e., $\mathrm{Al}^{3+}$ ) coordinated to the organic linker triazine-2,4,6-triyl-tribenzoic acid. ${ }^{138} \mathrm{PCN}-333$ was chosen since such a MOF-NP displays one of the highest void volumes and largest cages. As a result, PCN-333 acts as a single molecule traps for Hb thus minimizing Hb's aggregation and leaching. ${ }^{139}$ We demonstrated preservation of the excellent $\mathrm{O}_{2}$ binding and releasing properties of $\mathrm{Hb}$ following encapsulation within MOF-NPs. Additionally, to achieve extended circulation lifetimes in the blood stream, the Hb-loaded MOFNPs were camouflaged within erythrocyte derived cell membranes (Figure 7A). Such an approach is based on the "self-marker" biomolecules embedded within the lipid bilayer of natural RBCs. ${ }^{140,141}$ Successful coating by the cell membranes was demonstrated by the decreased protein adsorption and cell uptake by mouse macrophages for the coated MOF-NPs (Figure 7B and C).

Mesoporous silica NPs (MSNs) have been successfully employed for Hb encapsulation. ${ }^{142}$ In such a study, Hb was encapsulated inside pores with an average size of $10 \mathrm{~nm}$. The Hb-loaded MSNs were next coated by a lipid layer-containing PEG. However, the $\mathrm{O}_{2}$-binding and releasing properties of the encapsulated $\mathrm{Hb}$ still remain to be evaluated.

Particles with comparable size and shape to biological RBCs have also been fabricated. She et al. fabricated microparticles with similar shape and size than RBCs by making use of calcium hydroxide biconcave particles which were used as templates. ${ }^{143}$ The biconcave templates were subsequently coated by alternating layers of polyallylamine and GA and, following dissolution of the core template, capsules with a size and shape resembling RBCs were obtained.

The DeSimone group employed the particle replication in non-wetting templates (PRINT) technique to fabricate PEG-based particles of $6.3 \mu \mathrm{m}$ in diameter and $1.8 \mu \mathrm{m}$ in height. ${ }^{144}$ Importantly, the high elasticity of biological RBCs was also taken into account. Although the RBCs size is around $7.5 \mu \mathrm{m}$ in diameter, they routinely traverse blood capillaries smaller than $5 \mu \mathrm{m}$. This is a result of their high flexibility with a Young moduli of only $\sim 26 \mathrm{kPa} .{ }^{32}$ Actually, inspired by the elasticity of RBCs, soft polymeric particles have been engineered. Examples include PEG-based nanoparticles displaying a 130-fold lower modulus than RBCs. ${ }^{145}$ DeSimone employed a low crosslinking strategy which resulted in extremely deformable particles with the ability to pass through pores half as wide as the diameter of the particles employing a microfluidics device. Hb was incorporated by post-encapsulation and the authors were able to demonstrate preservation of the $\mathrm{O}_{2}$-binding and releasing properties as shown by UV-vis experiments.

A)

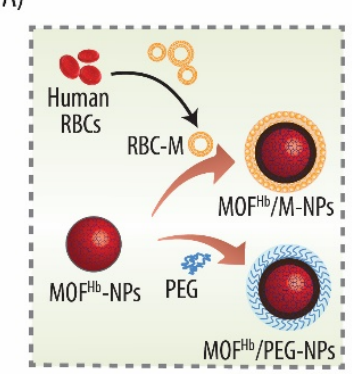

C) i) RAW 264.7 cells

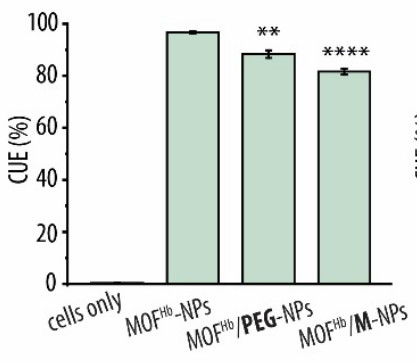

B) $\square$ BSA-FITC :BSA/IgG-FITC

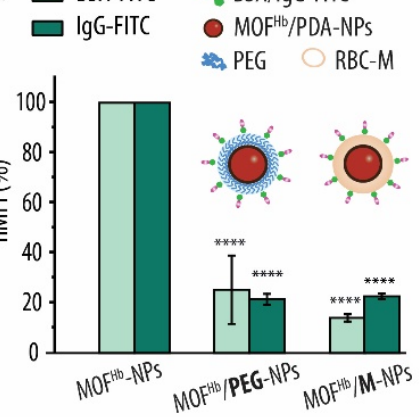

ii) HUVEC cells

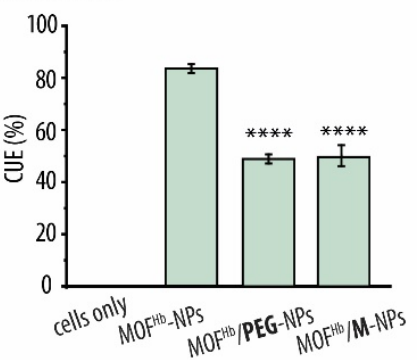

Fig. 7. A) Schematic illustration of the preparation of haemoglobin ( $\mathrm{Hb}$ )-loaded metal organic framework (MOF)-based nanoparticles (MOF ${ }^{\mathrm{Hb}}-\mathrm{NPs}$ ) with two different stealth layers, namely: a poly(ethylene glycol) (PEG) coating or a coating with membranes extracted from fresh red blood cells (RBC-M). B) Normalized mean fluorescence intensity (nMFI) of MOF ${ }^{\mathrm{Hb}}-\mathrm{NPs}$ with either a PEG (MOF ${ }^{\mathrm{Hb}} / \mathrm{PEG}-\mathrm{NPs}$ ) or a RBC-M (MOFHb/M-NPs) coating incubated in the presence of fluorescently labelled bovine serum albumin (BSA-FITC) or immunoglobulin G (IgG-FITC). C) Cell uptake efficiency (CUE) of RAW 264.7 (i) and HUVEC (ii) cells incubated with MOF ${ }^{\mathrm{Hb}}-\mathrm{NPs}$ with the different coatings. ${ }^{*} p \leq 0.05 ;{ }^{* *} p \leq 0.001,{ }^{* * *} p \leq 0.0005,{ }^{* * * *} \mathrm{p} \leq 0.0001$. Adapted with permission from ${ }^{138}$. Copyright 2020 Royal Society of Chemistry. 


\section{Future perspectives and outlook}

Blood, an intricate liquid composed of millions of chemicals and cells, is crucial for our survival. As such, for several decades, scientists have focused in replicating some of its properties in an attempt to create a blood surrogate. In particular, research efforts intensified in the 1980s, as a result of the HIV crisis, which emphasized how donor blood products could be the perfect source for spreading disease. As such, the creation of a blood surrogate is of utmost importance for countries with high HIV incidences. Additionally, novel infectious agents including Ebola, H1N1 (swine flu) or COVID-19 have emerged since the 1980s. A substitute for donor blood is also highly needed in emergency situations or in the context of natural (e.g., earthquakes) or man-made (e.g., plane crash, terrorist attacks) disasters. In this context, an important class of blood substitutes are the Hb-based oxygen carriers, which aim to take advantage of the oxygen transport properties of RBCs while overcoming some of its drawbacks since HBOCs will display: enhanced availability (by large-scale manufacture), universal applicability (by the absence of RBCs blood group antigens), absence of contamination risks (due to sterilization) and extended shelf life (stored in stable freeze-dried powder form).

Although research efforts have focused in developing a wide variety of HBOCs making use of diverse approaches and designs with some of them advancing to clinical trials, currently, no oxygen-carrying blood surrogate has been approved for human use in Europe or the US. Serious side effects were the main reason for not meeting the criteria for being approved by the FDA or EMEA. In particular, a meta-analysis of data from later stage clinical trials conducted in 2008, revealed that treatment with HBOCs resulted in enhanced risk of myocardial infarction and death. Such adverse events have been attributed to their renal clearance and the associated nephrotoxicity, NO scavenging and the resulting vasoconstriction and heme-mediated oxidative reactions.

As a result of the shortcomings of this first generation of blood substitutes, we know now that this is a complex field that needs much basic research to validate the proposed issues and theories. Only by obtaining such an important information, it will be possible to develop effective and safe $\mathrm{Hb}$-based blood surrogates. Approaches to address these side toxicities are on the way. In particular, novel HBOCs involve Hb's chemical modification (e.g., HemoTech) or its encapsulation within a protective carrier shell (e.g., $\mathrm{Hb}$ vesicles, PDA-coatings, Erythromer). Studies to evaluate their pharmacokinetics and pharmacodynamics, ability for tissue oxygenation and in vivo safety are currently being conducted and time will tell whether the toxicity issues of the first generation of HBOCs have been successfully mitigated.

Despite the progress, another important concern is their short vasculature residence time. While donor RBCs circulate in the bloodstream for about 28 days, circulation life times of HBOCs that are currently being developed are only in the range of 12 to 48 h. This highlights the fact that HBOCs might find an application in situation-specific scenarios when donor blood is not available. Thus, the more recent studies on HBOCs have shifted the focus from blood replacement to oxygen therapeutics. Such artificial oxygen carriers may find applications in pre-hospital settings, en route scenarios or to provide emergency care in remote civilian and battlefield locations. Within this framework, a clinical study design should systematically compare the administration of HBOCs to the relevant "standard of care" in pre-hospital trauma (i.e., administration of saline or plasma expanders instead of donor blood).

While the production of a liquid able to replace for donor blood is still a dream, the current development of HBOCs may pave the way towards the creation of a first generation of safe oxygen carriers to be used as a bridging solution making possible the management of bleeding in situations where donor blood is not available (e.g., in emergency prehospital and en route scenarios or remote locations).

\section{Conflicts of interest}

There are no conflicts to declare.

\section{References}

1

W. L. Liu, T. Liu, M. Z. Zou, W. Y. Yu, C. X. Li, Z. Y. He, M. K. Zhang, M. D. Liu, Z. H. Li, J. Feng and X. Z. Zhang, Adv. Mater., 2018, 30, 1802006.

A. Sen Gupta and A. Doctor, in Damage Control Resuscitation, 2020, pp. 197-222.

C. Bialas, C. Moser and C. A. Sims, J. Trauma Acute Care Surg., 2019, 87, S48-S58.

A. P. Cap, H. F. Pidcoke, M. DePasquale, J. F. Rappold, E. Glassberg, H. S. Eliassen, C. K. Bjerkvig, T. K. Fosse, S. Kane, P. Thompson, R. Sikorski, E. Miles, A. Fisher, K. R. Ward, P. C. Spinella and G. Strandenes, J. Trauma Acute Care Surg., 2015, 78, S2-S6.

P. C. Spinella, J. Dunne, G. J. Beilman, R. J. O'Connell, M. A. Borgman, A. P. Cap and F. Rentas, Transfusion, 2012, 52, $1146-1153$.

R. Chang, B. J. Eastridge and J. B. Holcomb, Wilderness Environ. Med., 2017, 28, S124-S134.

A. D’Alessandro, A. G. Kriebardis, S. Rinalducci, M. H. Antonelou, K. C. Hansen, I. S. Papassideri and L. Zolla, Transfusion, 2015, 55, 205-219.

D. V. Devine and K. Serrano, Clin. Lab. Med., 2010, 30, 475-487.

The Global Blood Industry | BCC Research, https://www.bccresearch.com/market-research/healthcare/global-blood-industry- 
report.html, (accessed 12 October 2020).

M. Njoku, D. St Peter, C. F. Mackenzie, D. S. Peter and C. F. Mackenzie, Br. J. Hosp. Med., 2015, 76, 78-83.

J. P. Acker, D. C. Marks and W. P. Sheffield, J. Blood Transfus., 2016, 2016, 1-28.

F. Noorman, T. T. C. F. Van Dongen, M. C. J. Plat, J. F. Badloe, J. R. Hess and R. Hoencamp, PLoS One, 2016, 11, e0168401.

H. F. Pidcoke, S. J. McFaul, A. K. Ramasubramanian, B. K. Parida, A. G. Mora, C. G. Fedyk, K. K. Valdez-Delgado, R. K. Montgomery, K. M. Reddoch, A. C. Rodriguez, J. K. Aden, J. A. Jones, R. S. Bryant, M. R. Scherer, H. L. Reddy, R. P. Goodrich and A. P. Cap, Transfusion, 2013, 53, 137S-149S.

D. S. Kauvar, J. B. Holcomb, G. C. Norris and J. R. Hess, J. Trauma Acute Care Surg., 2006, 61, 181-184.

J. Simoni, Artif. Organs, 2017, 41, 316-318.

C. L. Modery-Pawlowski, L. L. Tian, V. Pan, K. R. McCrae, S. Mitragotri and A. Sen Gupta, Biomaterials, 2013, 34, 526-541.

T. M. S. Chang, Artif. Cells, Nanomedicine Biotechnol., 2015, 43, 145-147.

R. Sender, S. Fuchs and R. Milo, PLOS Biol., 2016, 14, 1-14.

L. Dean, in The ABO blood group, National Center for Biotechnology Information (US), 2005, p. Chapter 5.

X. Wang, W. Gao, W. Peng, J. Xie and Y. Li, Artif. Cells, Blood Substit. And Biotechnol., 2009, 37, 41-44.

H. L. ; Goldsmith, J. Marlow and F. Campbell, Proc. R. Soc. London., 1972, 182, 351-384.

A. Sen Gupta, WIREs Nanomed. Nanobiotechnol., 2017, 9, e1464.

D. Z. de Back, E. B. Kostova, M. van Kraaij, T. K. van den Berg and R. van Bruggen, Front. Physiol., 2014, 5, 1-11.

T. Imamura, Nihon Rinsho., 1996, 54, 2320-2325.

L. Kaestner and A. Bogdanova, Front. Physiol., 2014, 5, 269-279.

S. Patel and S. S. Mohiuddin, Physiology, Oxygen Transport And Carbon Dioxide Dissociation Curve, StatPearls Publishing, 2020.

A. Madan, Lung India, 2017, 34, 307-308.

K. B. Ferenz and A. U. Steinbicker, J. Pharmacol. Exp. Ther., 2019, 369, 300-310.

C. Geers and G. Gros, Physiol. Rev., 2000, 80, 681-715.

V. Kuhn, L. Diederich, T. C. S. Keller, C. M. Kramer, W. Lückstädt, C. Panknin, T. Suvorava, B. E. Isakson, M. Kelm and M. M. CorteseKrott, Antioxid. Redox Signaling, 2017, 26, 718-742.

F. B. Jensen, Acta Physiol. Scand., 2004, 182, 215-227.

M. M. T. Jansman and L. Hosta-Rigau, Adv. Colloid Interface Sci., 2018, 260, 65-84.

B. W. Allen, J. S. Stamler and C. A. Piantadosi, Trends Mol. Med., 2009, 15, 452-460.

J. T. Ludlow, R. G. Wilkerson and T. M. Nappe, Methemoglobinemia, StatPearls Publishing, 2020.

H. F. Bunn, W. T. Esham and R. W. Bull, J. Exp. Med., 1969, 129, 909-924.

P. W. Buehler, F. D'Agnillo and D. J. Schaer, Trends Mol. Med., 2010, 16, 447-457.

D. B. Kim-Shapiro, A. N. Schechter and M. T. Gladwin, Arterioscler. Thromb. Vasc. Biol., 2006, 26, 697-705.

H. Sakai, K. Sou, H. Horinouchi, K. Kobayashi and E. Tsuchida, Artif. Organs, 2009, 33, 139-145.

X. Zhang and P. Zhang, Curr. Nanosci., 2017, 13, 124-129.

C. Natanson, S. J. Kern, P. Lurie, S. M. Banks and S. M. Wolfe, JAMA, 2008, 299, 2304-2312.

J. S. Jahr, M. Moallempour and J. C. Lim, Expert Opin. Biol. Ther., 2008, 8, 1425-1433.

D. M. Rogers and K. P. Crookston, Transfusion, 2006, 46, 1471-1477.

M. Mer, E. Hodgson, L. Wallis, B. Jacobson, L. Levien, J. Snyman, M. J. Sussman, M. James, A. van Gelder, R. Allgaier and J. S. Jahr, Transfusion, 2016, 56, 2631-2636.

D. Ortiz, M. Barros, S. Yan and P. Cabrales, Am. J. Emerg. Med., 2014, 32, 248-255.

R. B. Weiskopf, A. M. Beliaev, A. Shander, N. R. Guinn, A. P. Cap, P. M. Ness and T. A. Silverman, Transfusion, 2017, 57, $207-214$.

P. Cabrales and M. Intaglietta, ASAIO J., 2013, 59, 337-54.

A. Staub, S. Rudaz, M. Saugy, J.-L. Veuthey and J. Schappler, Electrophoresis, 2010, 31, 1241-1247.

K. M. Bobofchak, E. Tarasov and K. W. Olsen, Biochim. Biophys. Acta, - Proteins Proteomics, 2008, 1784, 1410-1414.

K. D. Vandegriff and R. M. Winslow, Artif. Organs, 2009, 33, 133-138.

B. Li, T. Li, G. Chen, X. Li, L. Yan, Z. Xie, X. Jing and Y. Huang, Macromol. Biosci., 2013, 13, 893-902.

S. Moradi, A. Jahanian-Najafabadi and M. H. Roudkenar, Clin. Med. Insights Blood Disord., 2016, 9, 33-41.

R. M. Winslow, Vox Sang., 2006, 91, 102-110.

J. S. Jahr, A. Sadighi Akha and R. J. Holtby, Curr. Drug Discov. Technol., 2012, 9, 158-165.

C. Olofsson, T. Ahl, T. Johansson, S. Larsson, P. Nellgård, S. Ponzer, B. Fagrell, R. Przybelski, P. Keipert, N. Winslow and R. M. Winslow, Anesthesiology, 2006, 105, 1153-1163.

R. M. Winslow, Artif. Organs, 2004, 28, 800-806.

K. D. Vandegriff, M. A. Young, J. Lohman, A. Bellelli, M. Samaja, A. Malavalli and R. M. Winslow, Br. J. Pharmacol., 2008, 154, 16491661.

J. A. Araujo, Blood, 2013, 122, 2535-2536.

P. E. Keipert, Adv. Exp. Med. Biol., 2016, 923, 23-29.

J. D. Belcher, M. Young, C. Chen, J. Nguyen, K. Burhop, P. Tran and G. M. Vercellotti, Blood, 2013, 122, 2757-2764. 
60 A. Abuchowski, in Advances in Experimental Medicine and Biology, Springer New York LLC, 2016, vol. 876, pp. 461-467.

61 J. Zhang, S. Cao, H. Kwansa, D. Crafa, K. K. Kibler and R. C. Koehler, J. Appl. Physiol., 2012, 113, 1709-1717.

62 J. A. Posluszny and L. M. Napolitano, Transfusion, 2014, 54, 3026-3034.

63 L. M. S. Resar, E. C. Wick, T. N. Almasri, E. A. Dackiw, P. M. Ness and S. M. Frank, Transfusion, 2016, 56, $2637-2647$.

V. Mallet, D. Dutheil, V. Polard, M. Rousselot, E. Leize, T. Hauet, J. M. Goujon and F. Zal, Artif. Organs, 2014, 38, 691-701.

S. A. Hosgood, E. van Heurn and M. L. Nicholson, Transpl. Int., 2015, 28, 657-664.

A. K. Salahudeen, Am. J. Physiol. - Ren. Physiol., 2004, 287, F181-F187.

J. M. Weinberg, Kidney Int., 1991, 39, 476-500.

M. Glorion, V. Polard, F. Favereau, T. Hauet, F. Zal, E. Fadel and E. Sage, Artif. Cells, Nanomedicine, Biotechnol., 2018, 46, 1773-1780.

E. S. Teh, F. Zal, V. Polard, P. Menasché and D. J. Chambers, Artif. Cells, Nanomedicine, Biotechnol., 2017, 45, 717-722.

A. I. Alayash, Shock, 2019, 52, 41-49.

T. A. Silverman and R. B. Weiskopf, Anesthesiology, 2009, 111, 946-963.

A. I. Alayash, Trends Biotechnol., 2014, 32, 177-185.

D. Nelson, M. Azari, R. Brown, K. Burhop, S. Bush, J. Catarello, H. Chuang, C. Downing, T. Estep, A. Loewen, K. McClure, A. McDaniel, E. Michalek, N. Mozier, K. Rohn, J. Spicuzza, P. Zieske and G. Zimmerman, Biomater. Artif. Cells Immobil. Biotechnol., 1992, 20, 423427.

M. L. Lamy, E. K. Daily, J. F. Brichant, R. P. Larbuisson, R. H. Demeyere, E. A. Vandermeersch, J. J. Lehot, M. R. Parsloe, J. C. Berridge, C. J. Sinclair, J. F. Baron and R. J. Przybelski, Anesthesiology, 2000, 92, 646-656.

R. Saxena, A. D. Wijnhoud, H. Carton, W. Hacke, M. Kaste, R. J. Przybelski, K. N. Stern and P. J. Koudstaal, Stroke, 1999, 30, 993-996.

C. P. Stowell, J. Levin, B. D. Spiess and R. M. Winslow, Transfusion, 2001, 41, 287-299.

J. Y. Chen, M. Scerbo and G. Kramer, Clinics, 2009, 64, 803-813.

E. P. Sloan, M. D. Koenigsberg, N. B. Philbin and W. Gao, J. Trauma Inj. Infect. Crit. Care, 2010, 68, 1158-1171.

C. L. Varnado, T. L. Mollan, I. Birukou, B. J. Z. Smith, D. P. Henderson and J. S. Olson, Antioxid. Redox Signaling, 2013, 18, $2314-2328$. R. M. Winslow, Annu. Rev. Med., 1999, 50, 337-353.

S. A. Gould, E. E. Moore, D. B. Hoyt, J. M. Burch, J. B. Haenel, J. Garcia, R. DeWoskin and G. S. Moss, J. Am. Coll. Surg., 1998, 187, 113-120.

D. C. H. Cheng, C. D. Mazer, R. Martineau, A. Ralph-Edwards, J. Karski, J. Robblee, B. Finegan, R. I. Hall, R. Latimer and A. Vuylsteke, J. Thorac. Cardiovasc. Surg., 2004, 127, 79-86.

G. T. Kinasewitz, C. T. Privalle, A. Imm, J. S. Steingrub, J. T. Malcynski, R. A. Balk and J. Deangelo, Crit. Care Med., 2008, 36, 19992007.

J. P. Harrington, J. Wollocko, E. Kostecki and H. Wollocko, Artif. Cells, Blood Substit. And Biotechnol., 2011, 39, 12-18.

P. S. Reynolds, R. W. Barbee, M. D. Skaflen and K. R. Ward, Shock, 2007, 28, 45-52.

J. Simoni, G. Simoni, D. E. Wesson and M. Feola, Curr. Drug Discov. Technol., 2012, 9, 173-187.

J. Simoni, G. Simoni, J. F. Moeller, M. Feola and D. E. Wesson, Artif. Organs, 2014, 38, 684-690.

C. J. C. Hsia and L. Ma, Artif. Organs, 2012, 36, 215-220.

D. K. Shellington, L. Du, X. Wu, J. Exo, V. Vagni, L. Ma, K. Janesko-Feldman, R. S. B. Clark, H. Bayir, C. E. Dixon, L. W. Jenkins, C. J. C. Hsia and P. M. Kochanek, Crit. Care Med., 2011, 39, 494-505.

D. Tomita, T. Kimura, H. Hosaka, Y. Daijima, R. Haruki, K. Ludwig, C. Böttcher and T. Komatsu, Biomacromolecules, 2013, 14, 18161825.

R. Haruki, T. Kimura, H. Iwasaki, K. Yamada, I. Kamiyama, M. Kohno, K. Taguchi, S. Nagao, T. Maruyama, M. Otagiri and T. Komatsu, Sci. Rep., 2015, 5, 1-9. 
Z. Tao and P. P. Ghoroghchian, Trends Biotechnol., 2014, 32, 466-473.

H. Sakai, J. Funct. Biomater., 2017, 8, 10-20.

V. R. Yadav, G. Rao, H. Houson, A. Hedrick, S. Awasthi, P. R. Roberts and V. Awasthi, Eur. J. Pharm. Sci., 2016, 93, 97-106.

M. Kohno, T. Ikeda, R. Hashimoto, Y. Izumi, M. Watanabe, H. Horinouchi, H. Sakai, K. Kobayashi and M. Iwazaki, PLoS One, 2017, 12, 1-16.

H. Agashe and V. Awasthi, Adv. Planar Lipid Bilayers Liposomes, 2009, 9, 1-28.

A. Pape, H. Kertscho, J. Meier, O. Horn, M. Laout, M. Steche, M. Lossen, A. Theisen, B. Zwissler and O. Habler, Intensive Care Med., 2008, 34, 1534-1543.

A. Usuba, R. Motoki, Y. Ogata, K. Suzuki and T. Kami tani, Artif. Cells, Blood Substit. And Biotechnol., 1995, 23, 337-346.

Y. Ogata, H. Goto, T. Kimura and H. Fukui, Artif. Cells. Blood Substit. Immobil. Biotechnol., 1997, 25, 417-427.

E. Rideau, R. Dimova, P. Schwille, F. R. Wurm and K. Landfester, Chem. Soc. Rev., 2018, 47, 8572-8610.

S. Rameez, H. Alosta and A. F. Palmer, Bioconjug. Chem., 2008, 19, 1025-1032.

D. R. Arifin and A. F. Palmer, Biomacromolecules, 2005, 6, 2172-2181.

Y. Qi, T. Li, Y. Wang, X. Wei, B. Li, X. Chen, Z. Xie, X. Jing and Y. Huang, Macromol. Biosci., 2016, 16, 906-913.

L. Duan, X. Yan, A. Wang, Y. Jia and J. Li, ACS Nano, 2012, 6, 6897-6904.

Y. Xiong, Z. Z. Liu, R. Georgieva, K. Smuda, A. Steffen, M. Sendeski, A. Voigt, A. Patzak and H. Bäumler, ACS Nano, 2013, 7, 74547461.

M. J. Cohen, M. Kutcher, B. Redick, M. Nelson, M. Call, M. Knudson, M. A. Schreiber, E. M. Bulger, P. Muskat, L. H. Alarcon, J. G. Myers, M. H. Rahbar, K. J. Brasel, H. A. Phelan, D. J. Del Junco, E. E. Fox, C. E. Wade, J. B. Holcomb, B. A. Cotton and N. Matijevic, J. Trauma Acute Care Surg., 2013, 75, S40-S47.

M. Wu, K. Feng, Q. Li, H. Ma, H. Zhu, Y. Xie, G. Yan, C. Chen and K. Yan, Artif. Cells, Nanomedicine, Biotechnol., 2018, 46, 47-55.

S. Guo, P. Wang, C. Chen, Z. Meng, D. Qi and X. Wang, Artif. Cells, Nanomedicine Biotechnol., 2016, 44, 1075-1079.

C. J. Roche, M. B. Cassera, D. Dantsker, R. E. Hirsch and J. M. Friedman, J. Biol. Chem., 2013, 288, 22408-22425.

Y. Liu, K. Ai and L. Lu, Chem. Rev., 2014, 114, 5057-5115.

Q. Wang, R. Zhang, M. Lu, G. You, Y. Wang, G. Chen, C. Zhao, Z. Wang, X. Song, Y. Wu, L. Zhao and Z. H. Zhou, Biomacromolecules, 2017, 18, 1333-1341.

O. Baidukova, Q. Wang, S. Chaiwaree, D. Freyer, A. Prapan, R. Georgieva, L. Zhao and H. Bäumler, Artif. Cells, Nanomedicine, Biotechnol., 2018, 46, S693-S701.

J. Hu, Q. Wang, Y. Wang, G. You, P. Li, L. Zhao and H. Zhou, J. Colloid Interface Sci., 2020, 571, 326-336.

X. Liu, M. M. T. Jansman, P. W. Thulstrup, A. C. Mendes, I. S. Chronakis and L. Hosta-Rigau, Macromol. Biosci., 2020, 20, 1900293.

S. Yuan, L. Feng, K. Wang, J. Pang, M. Bosch, C. Lollar, Y. Sun, J. Qin, X. Yang, P. Zhang, Q. Wang, L. Zou, Y. Zhang, L. Zhang, Y. Fang, J. Li and H. C. Zhou, Adv. Mater., 2018, 30.

A. J. Howarth, Y. Liu, P. Li, Z. Li, T. C. Wang, J. T. Hupp and O. K. Farha, Nat. Rev. Mater., 2016, 1, 1-15. J. S. Qin, S. Yuan, C. Lollar, J. Pang, A. Alsalme and H. C. Zhou, Chem. Commun., 2018, 54, 4231-4249.

M. A. Luzuriaga, R. P. Welch, M. Dharmarwardana, C. E. Benjamin, S. Li, A. Shahrivarkevishahi, S. Popal, L. H. Tuong, C. T. Creswell and J. J. Gassensmith, ACS Appl. Mater. Interfaces, 2019, 11, 9740-9746.

M. B. Majewski, A. J. Howarth, P. Li, M. R. Wasielewski, J. T. Hupp and O. K. Farha, CrystEngComm, 2017, 19, 4082-4091.

X. Lian, Y. Fang, E. Joseph, Q. Wang, J. Li, S. Banerjee, C. Lollar, X. Wang and H. C. Zhou, Chem. Soc. Rev., 2017, 46, 3386-3401.

F. Wu, J. Ye, Y. Cao, Z. Wang, T. Miao and Q. Shi, Luminescence, 2020, 35, 440-446.

S. Peng, J. Liu, Y. Qin, H. Wang, B. Cao, L. Lu and X. Yu, ACS Appl. Mater. Interfaces, 2019, 11, 35604-35612.

X. Liu, M. M. T. Jansman and L. Hosta-Rigau, Biomater. Sci., , DOI:10.1039/DOBM01118E.

D. Feng, T. F. Liu, J. Su, M. Bosch, Z. Wei, W. Wan, D. Yuan, Y. P. Chen, X. Wang, K. Wang, X. Lian, Z. Y. Gu, J. Park, X. Zou and H. C. Zhou, Nat. Commun., 2015, 6, 1-8.

C.-M. M. J. Hu, R. H. Fang and L. Zhang, Adv. Healthc. Mater., 2012, 1, 537-547.

R. H. Fang, Y. Jiang, J. C. Fang and L. Zhang, Biomaterials, 2017, 128, 69-83.

J. Tu, J. Bussmann, G. Du, Y. Gao, J. A. Bouwstra and A. Kros, Int. J. Pharm., 2018, 543, 169-178.

S. She, Q. Li, B. Shan, W. Tong and C. Gao, Adv. Mater., 2013, 25, 5814-5818.

T. J. Merkel, S. W. Jones, K. P. Herlihy, F. R. Kersey, A. R. Shields, M. Napier, J. C. Luft, H. Wu, W. C. Zamboni, A. Z. Wang, J. E. Bear and J. M. DeSimone, Proc. Natl. Acad. Sci. U. S. A., 2011, 108, 586-91.

J. Cui, M. Björnmalm, K. Liang, C. Xu, J. P. Best, X. Zhang and F. Caruso, Adv. Mater., 2014, 26, 7295-7299.

Y. Le Meur, L. Badet, M. Essig, A. Thierry, M. Büchler, S. Drouin, C. Deruelle, E. Morelon, F. Pesteil, P. Delpech, J. Boutin, F. Renard and B. Barrou, Am. J. Transplant., 2020, 20, 1729-1738.

H. Hosaka, R. Haruki, K. Yamada, C. Böttcher and T. Komatsu, PLoS One, 2014, 9, e110541. 